\title{
The Impact of Vertical Densification on Public Lighting in Informal Settlements: Using Virtual Environments as an Evaluation Tool for Policy Making
}

\author{
By David Michael Kretzer ${ }^{*}$ \& Michael Walczak ${ }^{ \pm}$
}

\begin{abstract}
There are a variety of reasons to support the premise that public lighting is beneficial to urban communities. At the same time, a key challenge for the provision of public lighting in informal settlements is their constant physical transformation. The aim of this paper is to evaluate the application of virtual environments (VES) in lighting planning and policy making. Despite the fact that VEs offer the opportunity to explore an environment by freely navigating through it, including environments that change over time, this feature is rarely taken into account in decision-making processes. A VE-based analysis tool for informal settlement lighting is presented using a case-study street in the informal settlement of Caracolí in Bogotá as its basis. The main data set for the VE scenarios was comprised of results from a household survey, spatial measurements, and participant observations as well as luminous intensity distribution curves. The household survey was used to collect time-related data on the incremental construction of Caracoli's informal dwellings, which was then projected into past, present, and future night-time scenarios. The lighting quality of these different scenarios was systematically evaluated via lighting calculation software, revealing a variety of shortcomings caused by the current lighting approach. Based on these findings, an alternative lighting approach was developed and re-examined using lighting calculations. Finally, custom game-engine technology and GPU computing were deployed, which allowed for real-time visualisation of the different lighting scenarios and their lighting quality. This setup therefore enables fast iterative feedback loops for current and future lighting policy scenarios and the resulting lighting design. In the first instance, a VE can illustrate well how current lighting policy results in a significant delay of lighting provision in the early stage of a settlement as well as highlight the mismatch between lighting technology and the built environment during the vertical densification phases. Second, the VE is able to showcase alternative lighting technologies and policy approaches as well as the resulting lighting effects, enabling a visual comparison of different policy scenarios over several decades. In conclusion it will be argued that the dynamic VE technology appears to be a promising decision-making tool for illustrating potential planning and design shortcomings to policy stakeholders in a manner understandable to the layman.
\end{abstract}

\section{Introduction}

Informal settlements grow incrementally depending on the legal status of the dwelling lots and the financial resources of the residents. Consequently, dwelling material, dwelling width, dwelling length, and dwelling height are in a state of permanent transformation. In Bogotá, public lighting is provided by local authorities once informal settlements have reached formal legalisation. In contrast to the surrounding informal dwellings, the luminaires installed by the authorities

*PhD Student and Research Assistant, ETH Zurich, Switzerland.

${ }^{ \pm}$PhD Student, University of Applied Arts Vienna, Austria \& Research Assistant, ETH Zurich, Switzerland.

D. M. Kretzer and M. Walczak contributed equally to this work as first authors. 
constitute inflexible objects that remain constant over time. In addition, public luminaires of a similar height can be found in streets of significantly different widths (see Figure 1).
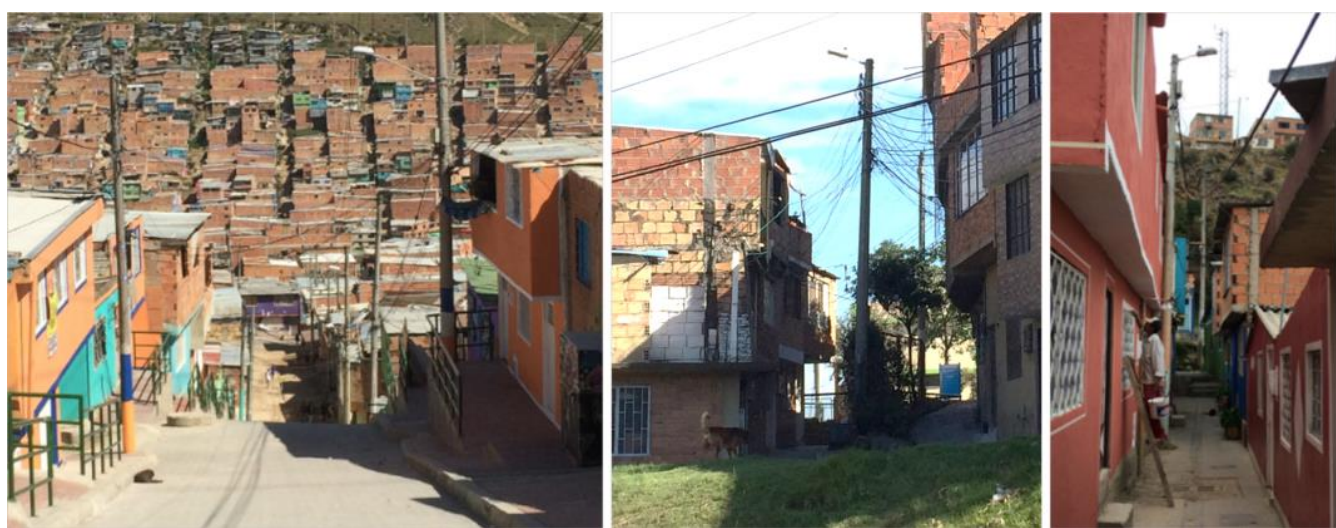

Figure 1. Luminaires of Similar Height Lighting a Nine-Metre-Wide (left-hand side), Less than Six-Metre-Wide (middle) and Less than Three-Metre-Wide (righthand side) Street

Source: Kretzer, 2017 \& 2018.

Lighting design tends to be a rather static process that is conducted before the installation of luminaires takes place. In a 'formally' built environment, it can be expected that the street and building design have been approved by a planning commission and that little physical change will take place in the future. Consequently, the lighting design is likely to be adequate for several decades. However, in an incrementally growing informal environment, the quality of the lighting design (done before the luminaire installation) is unlikely to be maintained over a long period of time. Hence, a virtual lighting-design planning process that considers future building-density scenarios is ideal. Virtual reality (VR) based on virtual environments (VE) represents a technological opportunity for time-related design planning of this type. Existing VE and VR frameworks permit real-time visualisations to be performed using GPU technology. This makes it possible to visually explore the planning outcomes by freely navigating within a virtual space. Custom coding enables the implementation of further large-scale datasets such as time, topography, architectural structures, and footfall (i.e. motion patterns of pedestrians). Virtual reality has its roots in conceptional and theoretical texts dating back to the 1930s, especially by filmmakers. More recently, VR has been gaining attention not only in the gaming industry, but also in scientific research including medication treatments, human decision-making, and analyses of human perception.

Lighting design is based on luminous intensity distribution files that contain the photometric characteristics of luminaires. Such files are provided by luminaire manufacturers and are compatible with both common lighting-calculation and VE software. Lighting-calculation software does in fact incorporate some aspects of VEs, such as a 3D-lit model that can be explored by navigation or a camera path. However, this does not unlock the full potential of game-engine technology, which 
can integrate dynamically changing objects and materials. A game engine offers for example the opportunity to custom-code and materialise incrementally densifying architectural structures or to custom-code moving people and cars.

The first objective of this paper is to evaluate in quantitative terms the lighting quality created by a constant lighting installation within a vertically densifying environment. This will then be compared with a non-constant alternative lighting approach.

The second objective of this paper is to understand the benefits a virtual environment offers for informal settlement lighting planning and policy making.

\section{Literature Review}

Public lighting for pedestrians is an important requirement for outdoor nighttime life in both formal and informal environments. It allows for adequate obstacle detection, ${ }^{1}$ reduces fear of crime, ${ }^{2}$ supports more use of outdoor facilities as well as economic growth, ${ }^{3}$ and improves people's orientation ${ }^{4}$ at night, to name a few examples. In terms of informal settlements, lighting can, for instance, support residents in safely finding their way to communal toilets at night, help them to avoid snakes and stray dogs, and enable them to run their businesses later into the night $^{5}$.

Nowadays, around a billion people live in informal living conditions, and 95\% of urban expansion over coming decades will take place in the developing world $^{6}$. Municipalities in many developing countries lack the ability to effectively deliver infrastructure and services to their citizens. ${ }^{7} \mathrm{UN}-\mathrm{Habitat}{ }^{8}$ cites the lack of basic services such as street lighting as a common characteristic of informal settlements. However, even in cases where informal settlements have already been formally supplied with public lighting, a lack of lighting can recur because of inmigration and expansion of the settlement boundaries. ${ }^{9}$ In some informal

1. S. Fotios and J. Uttley, "Illuminance Required to Detect a Pavement Obstacle of Critical Size," Lighting Research \& Technology 50, no. 3 (2018): 390-404.

2. Fotios, A. Liachenko Monteiro and J. Uttley, "Evaluation of Pedestrian Reassurance Gained by Higher Illuminances in Residential Streets using the Day-Dark Approach," Lighting Research \& Technology 51, no. 4 (2019): 557-575. 367.

3. P. R. Boyce, "The Benefits of Light at Night," Building and Environment 151 (2019): 356-

4. R. P. Leslie and P. A. Rodgers, The Outdoor Lighting Pattern Book (New York: McGrawHill Publishers, 1996).

5. D. M. Kretzer, "High-Mast Lighting as an Adequate Way of Lighting Pedestrian Paths in Informal Settlements?” Development Engineering (2020) DOI=10.1016/j.deveng.2020.100053.

6. United Nations 2015, Sustainable Development Goals. Retrieved from: www.un.org/sus tainabledevelopment/cities/. [Accessed 18 April 2019].

7. M. Majale, Enabling Shelter Strategies: Design and Implementation Guide for Policymakers (Nairobi: UN-Habitat, 2011).

8. UN-Habitat, The Challenge of Slums: Global Report on Human Settlements 2003. (London/ Sterling, VA: Earthscan, 2003).

9. D. Ravindra Prasad and A. Malla Reddy, Environmental Improvement of Urban Slums: The Indian Experience (Hyderabad: Booklinks Corporation, 1994). 
settlements, the residents compensate for such lack by installing self-built 'informal' luminaires in the public space. ${ }^{10}$

Informal settlements are characterised by constant physical transformation. ${ }^{11}$ Their building structures can emerge within a few days; ${ }^{12}$ hence, public space is subject to constant modification. The heights of informal dwellings can vary significantly - from one or two storeys up to as many as seven to ten storeys in height ${ }^{13}$ as a result of densification. Taubenböck, Kraff and Wurm ${ }^{14}$ discovered dwellings of up to four storeys in Makoko (Lagos) and Paraisópolis (São Paulo) as well as dwellings of up to seven storeys in Petare (Caracas) and Tondo (Manila), for instance. Such architectural structures grow incrementally over time, "mostly constructed through room-by-room accretion in a process driven by the imperatives of poverty and the slow accretion of resources." can often be found in spaces usually belonging to the public realm having acquired private character through use. ${ }^{16}$ Such spaces can be regarded as semi-public. ${ }^{17}$ In contrast to the formal city, where the street network comes first and the architecture plugs into it, in informal settlements the buildings come first and access networks co-emerge with them. ${ }^{18}$ Once public luminaires are installed in such environments, it can be expected that both the architecture as well as the public space will subsequently undergo physical transformation. Consequently, the lighting effect created at the beginning of a lighting installation changes over time. Furthermore, both the lighting effect created by the luminaires and also the luminaires as physical objects themselves may be affected by such incremental building growth: Brillembourg and Klumpner ${ }^{19}$ reveal how a pole-mounted

10. Kretzer, "The Relationship between Public Lighting and Urban Sustainability in Bogotá's Informal Settlements," in Transitioning to Sustainable Cities and Communities (ed.) H. Klumpner and K. E. Papanicolaou. Basel: MDPI, 2021. [In Review].

11. J. Hernández-García, Public Space in Informal Settlements: The Barrios of Bogotá (Newcastle upon Tyne: Cambridge Scholar Publishing, 2013).

12. See: P. M. Ward, "The Practice and Potential of Self-Help Housing in Mexico City," in Self-Help Housing: A Critique, 175-208 (ed.) by P. M. Ward. London: Mansell Publishing Limited, 1982.

13. D. Gouverneur, Planning and Design for Future Informal Settlements: Shaping the SelfConstructed City (Abingdon / New York: Routledge, 2015).

14. H. Taubenböck, N. J. Kraff and M. Wurm, "The Morphology of the Arrival City - A Global Categorization based on Literature Surveys and Remotely Sensed Data," Applied Geography 92 (2018): 150-167.

15. H. Kamalipour and K. Dovey, "Mapping the Visibility of Informal Settlements," Habitat International 85 (2019): 64.

16. V. Bhatt and W. Rybczynski, "How the Other Half Builds," in Time-Saver Standards for Urban Design, 1.3-1 - 1.3-12 (ed.) D. Watson, A. Plattus and R. Shibley. New York/Chicago/San Francisco/Lisbon/London/Madrid/Mexico City/Milan/New Delhi/San Juan/Seoul/Singapore/ Sydney/Toronto: McGraw-Hill, 2003.

17. Hernández-García, Public Space in Informal Settlements: The Barrios of Bogotá, 2013.

18. Kamalipour and Dovey, "Incremental Urbanism," in Mapping Urbanities: Morphologies, Flows, Possibilities, 249-267 (ed.) K. Dovey, E. Pafka and M. Ristic. Abington/New York: Routledge, 2018.

19. A. Brillembourg and H. Klumpner, "The Simple and Complex," in Informal City: Caracas Case, 216-226 (ed.) A. Brillembourg, K. Feireiss and H. Klumpner. Munich/Berlin/ London/New York: Prestel, 2005. 
luminaire has been absorbed completely over the years by an incrementally growing building in Caracas.

Kretzer $^{20}$ has evaluated the attempt to light informal settlements with highmast luminaires, showing that such lighting results in low illuminance uniformity. His study comprised solely single-storey dwellings to create a 'best case' scenario. Furthermore, Kretzer $^{21}$ analysed self-built 'informal luminaires' in Colombia, demonstrating that although they sometimes exhibit aspects of 'smart lighting' technology, at the same time they do not comply with product safety, efficiency, and light pollution standards.

Virtual environments (VEs) and their associated communication technique of virtual reality (VR) are being applied and deployed across a variety of fields. ${ }^{22}$ VR is an immersive visualisation that can follow human head and body motion through a head-mounted display. The strength of immersive environment exploration can be seen, for example, in "(...) using Virtual Reality as a therapeutic tool (...), [to] rely on VR simulations to perform a kind of exposure therapy wherein patients are asked to confront a traumatic experience or event in order to overcome it." ${ }^{23} \mathrm{VR}$ “(...) allows us to experience radically different environments and perspectives, and to challenge the dominant and habitual perceptual states we've come to know and understand." 24 Immersive experiences as a medium for communicating complex urban phenomena and spaces have not yet been explored extensively. $^{25}$

VR offers huge potential for application in the Global South, since many developing countries exhibit a fragmented provision of data as well as a lack of tools and methods for understanding the available data. ${ }^{26}$ Raw data, however, does not convey any information - in order to generate information and facilitate communication, it has to be organised and must make sense to any observer. ${ }^{27}$ The appropriate method of communication through the identification of more comprehensive ways of visualising, understanding, and engaging seems to support evidence-based decision and policy making. Human perception is primarily

20. Kretzer, "High-Mast Lighting as an Adequate Way of Lighting Pedestrian Paths in Informal Settlements?” 2020.

21. Kretzer, "The Relationship between Public Lighting and Urban Sustainability in Bogotá's Informal Settlements," 2021.

22. See: S. Greengard, Virtual Reality (Cambridge / London: The MIT Press, 2019); D. Landwehr, (ed.), Virtual Reality (Basel: Christoph Merian Verlag, 2019).

23. J. Kaganskiy, "New Ways of Seeing and Perceiving," in The Unframed World, Virtual Reality as Artistic Medium (ed.) Haus der elektronischen Künste Basel. Basel: Christoph Merian Verlag, 2017, 61.

24. Ibid.

25. J. Döllner, K. Baumann and H. Buchholz, "Virtual 3D City Models as Foundation of Complex Urban Information Spaces," $11^{\text {th }}$ International Conference on Urban Planning and Spatial Development in the Information Society. Vienna: CORP - Competence Center for Urban and Regional Development, 2006, 107-112.

26. K. Schechtner, "Big Data for Urban Change: Debunking the Myth \& a Way Forward," in Urban Change: Social Design - Arts as Urban Innovation, 117-123 (ed.) A. Falkeis. Basel: Birkhäuser, 2017.

27. M. R. Doyle, S. Savić and V. Bühlmann, Ghosts of Transparency: Shadows Cast and Shadows Cast out (Basel: Birkhäuser, 2019). 
vision-based, and modern society makes significant use of visual interfaces. ${ }^{28}$ Furthermore, Beck $^{29}$ argues that humans understand things much better in 3D. Care has to be taken in choosing the way we communicate and visualise information since it is evident that these factors can drastically affect the viewer's decision/point of view and potential research results. ${ }^{30}$ However, methods such as VR enable humans to understand cross-referenced parameters and their impacts on the built environment more easily. ${ }^{31}$ Visual media has the power to communicate complex facts in a comprehensible way and help more reasoned decisions to be made, enabling potential future scenarios to be imagined. In other words, longterm messages improve their chances of survival if they are reduced to the essentials: a sketch can be more meaningful than a drawing. ${ }^{32}$ In terms of lighting, Chen, Cui and $\mathrm{Hao}^{33}$ have shown that VR is more effective and reliable in presenting a lighting environment compared to videos and photos, as it is able to present several lighting attributes consistent with the physical environment. Furthermore, a daylight study by Chamilothori, Wienold and Andersen ${ }^{34}$ similarly concludes that no significant differences were observed between users' evaluation of the real and virtual environments.

Using pixel comparison, Walczak ${ }^{35}$ showed consistency in VR with regards to luminaires, the built environment, and resulting shadows as well as the perceived perspective compared to a photograph taken in the same location.

\section{Methodology}

Six main steps were performed in order to evaluate the lighting conditions within vertically densifying informal environments and to assess the benefits of virtual environments for both lighting planning and policy making:

Step 1: Data collection in an informal settlement street.

Step 2: $\quad$ Creation of a 3D model.

Step 3: Digital reconstruction of the current lighting.

Step 4: Lighting calculations of five different degrees of vertical densification (zero storeys, one storey, two storeys, three storeys,

28. W. J. Mitchell, Bildtheorie (Frankfurt am Main: Suhrkamp, 2018).

29. J. Beck, "Hyper Reality Pop," in Virtual Reality, 240-249 (ed.) D. Landwehr. Basel: Christoph Merian Verlag, 2019.

30. M. Walczak, "Qualitative Visualization of Quantitative Urban Models Impacting Policy Decision Making: A Case Study of Urban Infrastructure Interventions," 3. Doktorand_innen Symposium der Architektur. Linz: Kunstuniversität Linz, 2019.

31. Ibid.

32. R. Debray, Einführung in die Mediologie (Bern: Haupt Verlag, 2003).

33. Y. Chen, Z. Cui and L. Hao, "Virtual Reality in Lighting Research: Comparing Physical and Virtual Lighting Environments," Lighting Research \& Technology 51, no. 6 (2019): 820-837.

34. K. Chamilothori, J. Wienold and M. Andersen, "Adequacy of Immersive Virtual Reality for the Perception of Daylit Spaces: Comparison of Real and Virtual Environments," The Journal of the Illuminating Engineering Society 15, no. 2-3 (2019): 203-226.

35. Walczak, "Qualitative Visualization of Quantitative Urban Models Impacting Policy Decision Making: A Case Study of Urban Infrastructure Interventions,” 2019. 
and four storeys) for three different street widths (of seven metres, five metres and three metres, respectively) under the current lighting conditions.

Step 5: Lighting calculations in both the 'best case' and 'worst case' densification scenario of step 4, using an alternative two-phase lighting approach.

Step 6: Creation of a time-dynamic 4D virtual environment in order to illustrate the current lighting versus the alternative lighting approach, from the earliest reported construction data in the casestudy street (i.e. 1985) to 2052.

For step 1, a multi-method case study was conducted in a 183-metre-long pedestrian street (see Figure 2) in Bogotá's Caracolí settlement during January and February 2019. This included night-time street observations, spatial measurements, a household survey, a lighting audit, and illuminance measurements using a Konica Minolta CL-200 A. 88 metres of the street were lit by four high-pressure sodium street lights (referred to as 'formal' lighting), with the remaining 95 metres lit by nine self-built luminaires installed by the residents (referred to as 'informal' lighting). The street begins at an altitude of 2,720 metres and ends at an altitude of 2,770 metres, resulting in a very steep incline of over $35 \%$ (see Figure 3). The majority of the dwellings are regarded as illegal, having been built on land classified as high risk due to the threat of landslides.

Since informal settlements are characterised by permanent physical transformation, spatial measurements were conducted using a drone, a $360^{\circ}$ camera, a measuring wheel, a laser distance meter, and a measuring tape in order to document the neighbourhood. Both 'formal' and 'informal' self-built luminaires were analysed in terms of their geometrical and lighting characteristics. The luminaires' height, the lamp types and wattages as well as the horizontal illuminance directly beneath each luminaire were recorded. Furthermore, the horizontal illuminance along the entire informally lit part of the street was measured. One informal luminaire was shipped to Europe in order to measure and digitise its photometry in a goniophotometer (see Figures 4 and 5).

The purpose of observing the street was to analyse residents' night-time activities by mapping the number, type, and location of activities as well as to record people's age and gender. Such information can be expected to have an impact on how people evaluate fear of crime under certain lighting conditions. Observations were conducted during both a weekday and a weekend day. During the hours of participant observation, the researcher was able to overlook both the formally and informally lit part of the street simultaneously, standing at the threshold of both parts of the street. Walking was the main activity. Furthermore, other outdoor activities such as talking, playing, smoking, smartphone use, and cooking were observed.

The household survey was used to collect the construction data from 36 out of 52 dwellings. The main questions were in what year each of the dwelling storeys had been built and what materials had been used. The data was compared with Google Earth satellite images and corrected if necessary. For the 26 dwellings for 
which no survey was available, the construction dates of the first storey were estimated using satellite imagery or the data of neighbouring dwellings. The average duration until additional storeys (second and third storey respectively) had been constructed was used for the 26 dwellings without survey data, as well as for the storeys that will be constructed after 2019 .

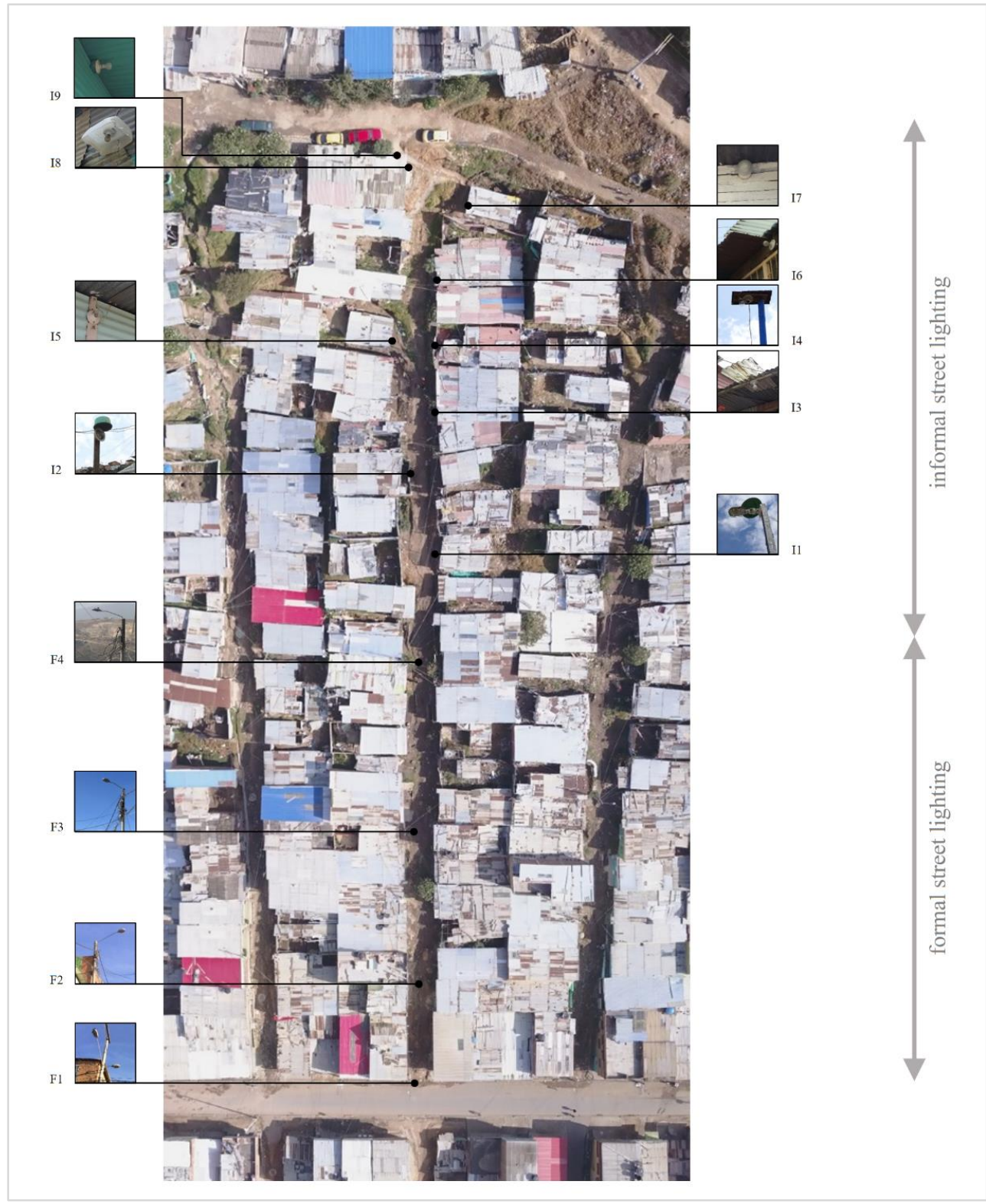

Figure 2. The Case-Study Street in Caracolí, Lit by Four Formal HighPressure Sodium Street Luminaires Provided by the Municipality (F1-F4) and Nine Informal Street Luminaires Provided by the Residents (I1-I9) Source: Kretzer, 2019.

For step 2, transforming the data gathered by drone and $360^{\circ}$ filming as well as distance measurements into a 3D model was a complex iterative process. The drone footage was the basis for establishing information about the plan view, 
combined with information provided by Google Earth satellite imagery and digital elevation maps from the NASA shuttle mission. The $360^{\circ}$ footage provided the vertical information for the model with regards to the number of building storeys as well as the location of windows, doors and stairs, the roof geometry, overhangs, terraces, materialisation, topography, and vegetation.

The static elements visualised within the VE/VR visualisation framework comprise the topography, buildings, vegetation as well as specific objects such as luminaires, fences, and tyres. Each of these elements is further explained in the following section.

As regards the static topography visualisation, the Geotiff raw data for Bogotá is accessed through the NASA shuttle mission. Within Q-GIS Version 3.4.8Madeira, the QGis2Threejs Plugin is used to convert Geotiff Data into gltf format. Aspose.3D Conversion ${ }^{36}$ is used for the translation from gltf to stl format, allowing the topography to be opened in Rhinoceros 3D and the format to be translated to Unreal Engine readable format (fbx). Additional elements such as trees, bushes, and significant objects are added and materialised manually through the Rhinoceros 3D and Unreal Engine workflow.

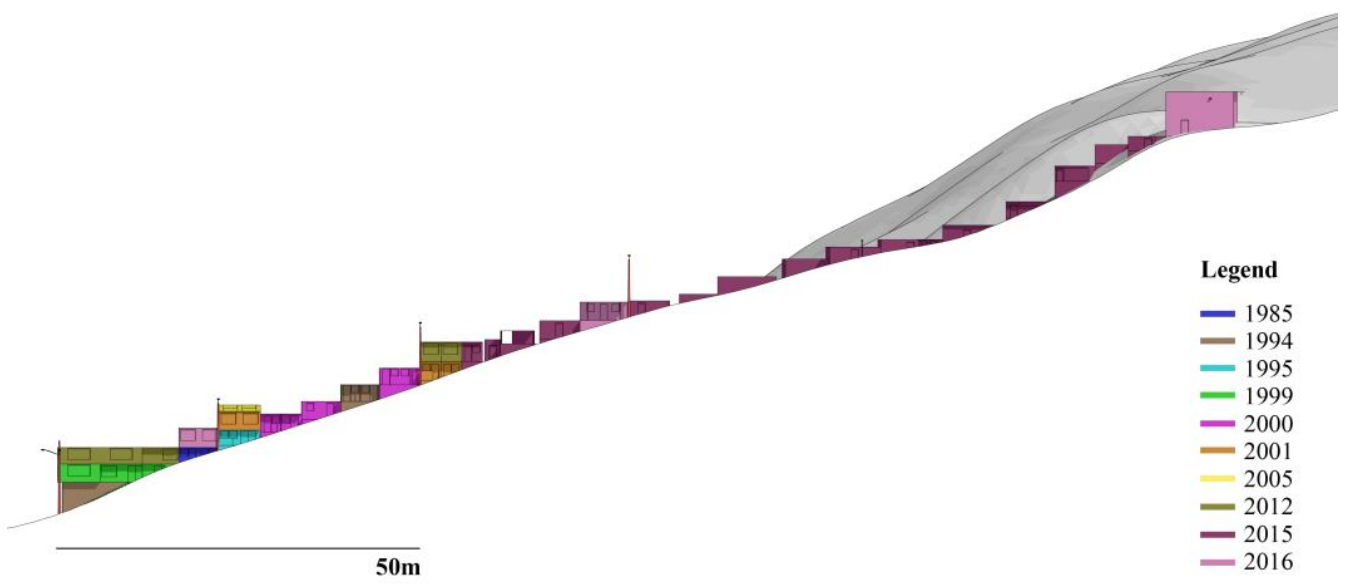

Figure 3. Section of the Case-Study Street Documented in 2019 Showing the Topography, Buildings with their Respective Color-Coded Construction Years, and the Location of Formal Lighting. This Planning Document was Produced via Automated Means Using the Unreal Engine and Rhinoceros 3D Framework. Source: Walczak, 2019.

Regarding the static building visualisation, the Unreal Engine is extended with custom $\mathrm{C}++$ code. GDAL Library is used for loading all geolocated building footprints and their respective numeric building storeys provided by 'Mapas Bogotá'. If no spatial building measurements could be taken the following method is applied: according to aggregated field observations, the building footprints are extruded by the multiplication of a 2.4-metre building height for the ground floor and 2.6 metres for all the subsequent floors, which have additional height for the ceiling compared to the ground floor which has its ground plate below ground

36. https://products.aspose.app/3d/conversion/gltf-to-stl. [Accessed 19 March 2020]. 
level. Another observed specificity is that the first floor (i.e. the second storey) on average overhangs the streetscape by approximately 0.6 metres. Each consecutive floor, starting from the second floor, was found to overhang the streetscape by an average of around 0.2 metres. Custom code relocates the buildings by their altitude to their respective position in accordance with the topography by finding their intersection point. The buildings are materialised and UV-mapped automatically with a selection of common materials in the settlement including bricks, corrugated steel, glass, and wood. Windows, doors, railings, specific roof geometries, and terraces are added and materialised manually through the Rhinoceros 3D workflow and Unreal Engine framework.

A computer-based simulation research strategy was conducted for step 3 . The lighting of the entire street (see Figure 2) was reconstructed in a lighting software program (see Figure 6) using the 3D model constructed in step 2 and photometric files. The software used for the calculation was Dialux 4.13. Each object within the model had matt surfaces with a reflectance of 0.5 , and the ground's matt surface had a reflectance of 0.3. Moreover, the informal luminaires had surface reflectances according to their object colours. A reflectance of 0.5 was chosen for the model objects (which are mainly architectural structures) as a value that represents a variety of building materials: dark red bricks have a reflectance of 0.1 to 0.15 , light grey concrete has a reflectance of 0.4 to 0.6 , and wood has a reflectance in the range of 0.1 to $0.5,{ }^{37}$ to name some examples. A reflectance of 0.3 was chosen for the ground since the street was unpaved and sandstone has a reflectance of 0.2 to $0.4 .^{38}$

The calculations consisted of two main parts. The lighting of the four formal luminaires (F1-F4) in the lower part of street (see Figure 2) was reconstructed by documenting the luminaire codes written on the housing of each luminaire. Based on these codes, the luminaire specifications were provided by Bogotá's public lighting authority. In this way, the luminaire manufacturer's photometric file could be identified and used for lighting calculations. The height of the luminaire heads was 9 meters; the spacing was 22.5 metres between luminaire F1 and F2, 29 meters between F2 and F3 and 29.5 metres between F3 and F4.

37. E. Neufert, Bauentwurfslehre, 42 (Wiesbaden: Springer Vieweg, 2019).

38. Ibid. 


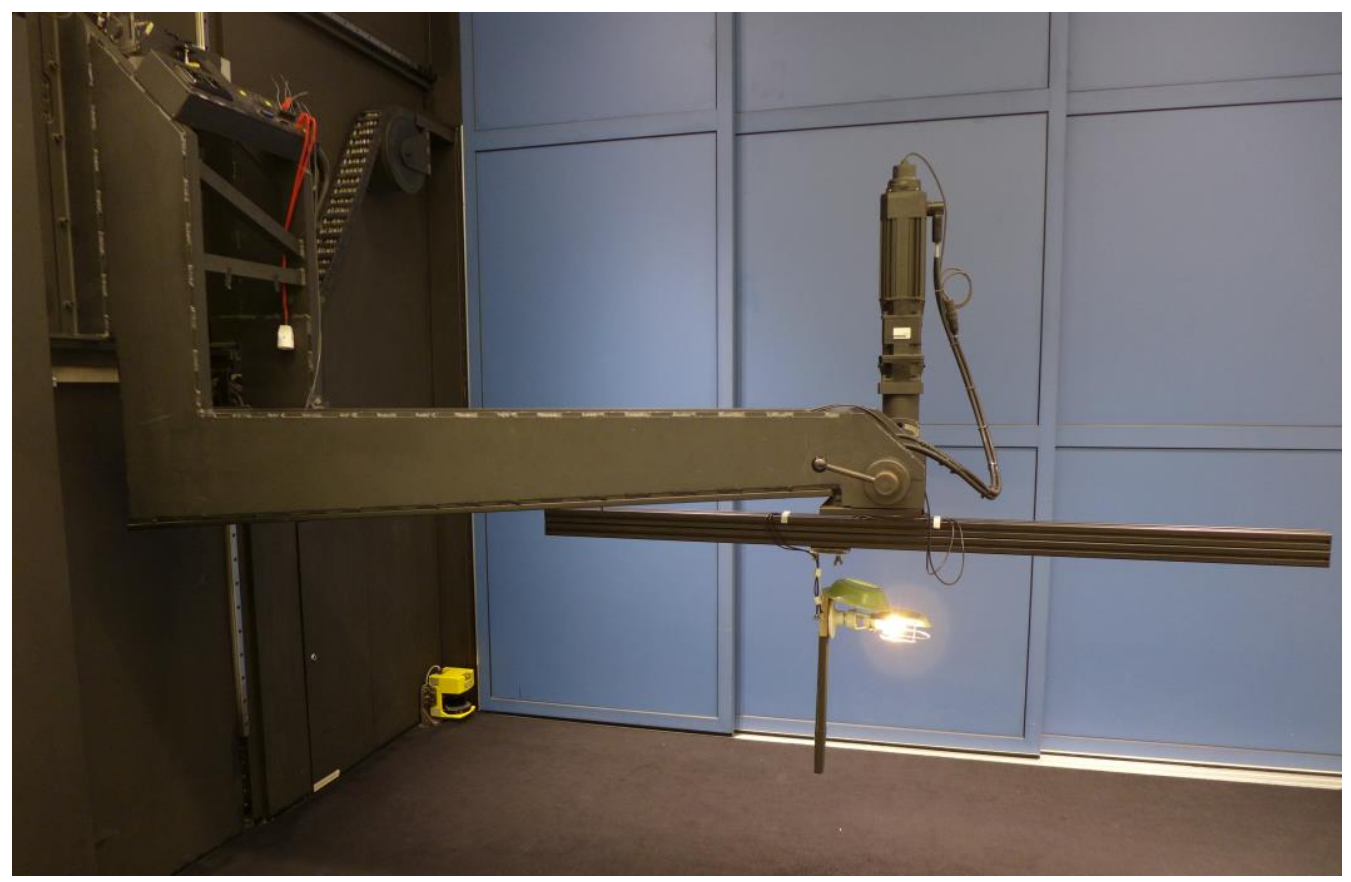

Figure 4. The Photometry of an Informal Luminaire is Measured in Zumtobel Lighting's Goniophotometer.

Source: Kretzer, 2020.

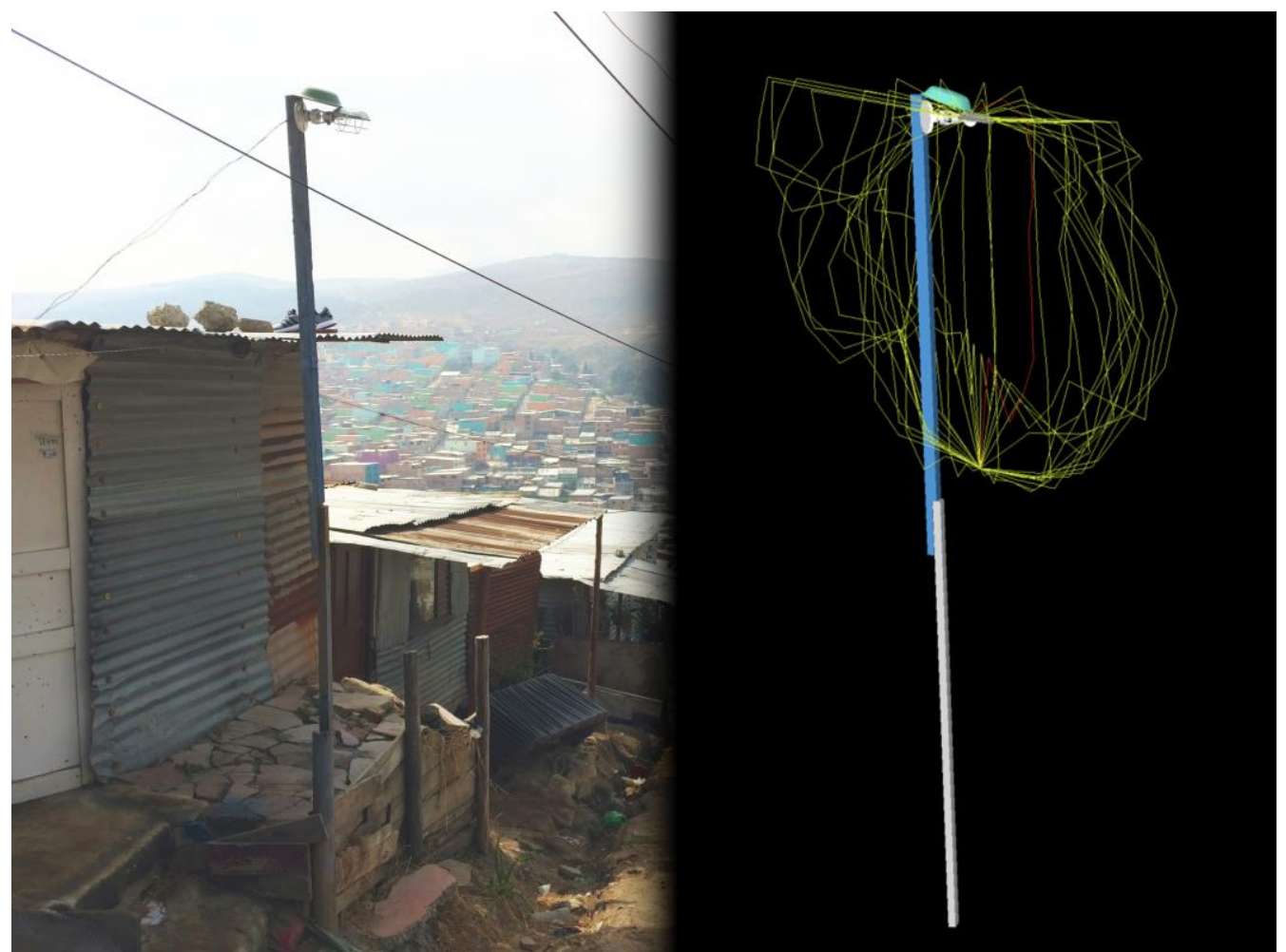

Figure 5. Digitisation Process of Informal Luminaires Including Physical and Photometric Information

Source: Kretzer and Walczak, 2020. 


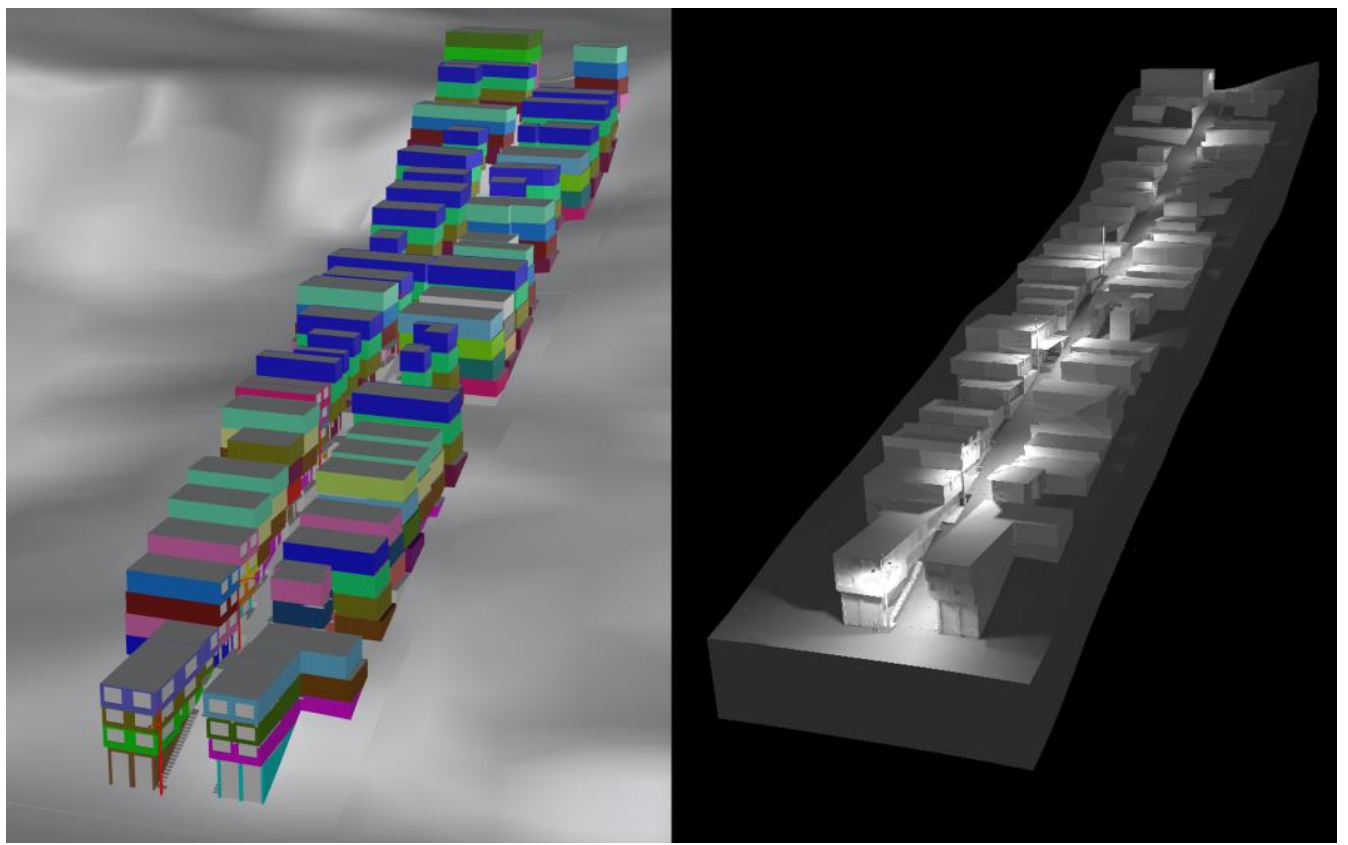

Figure 6. The 3D Model of the Four-Storey Case-Study Street Including ColorCoded Construction Years (Created in Rhinoceros 3D (left-hand side)) and the Lighting of the Formally and Informally Lit Parts of the Case-Study Street in 2019 (Reconstructed in the Dialux Lighting Software (right-hand side))

Source: 3D model: Walczak, 2019; lighting reconstruction: Kretzer, 2019-2020.

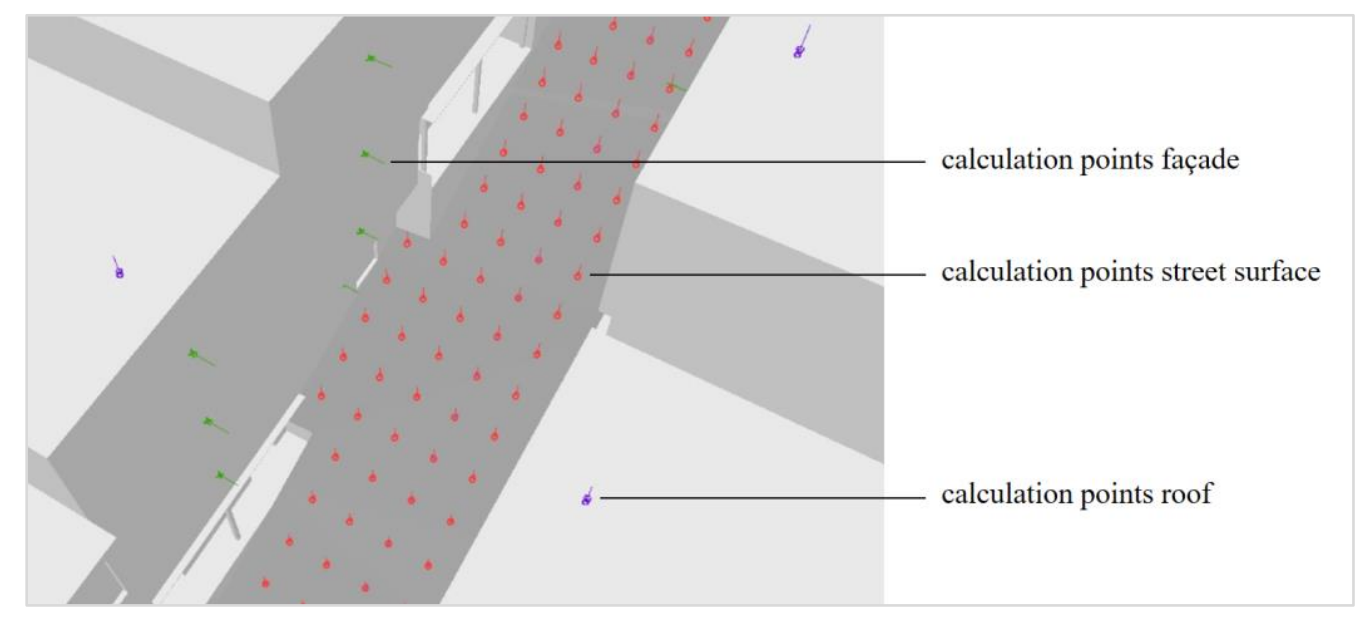

Figure 7. Calculation Point Positions: Street Surface (red), Façade (green), Roof (purple)

Source: Kretzer, 2020.

The lighting of the nine informal luminaires in the upper part of the street (see Figure 2) was reconstructed to ensure the correct lighting levels within the virtual environment software. The photometric file derived from a goniophotometer measurement was used for luminaire I1. Photometric files of comparable light sources were used for the other luminaires and integrated into 3D replicas of the 
informal luminaires. The lighting levels were adapted in Dialux 4.13 to the on-site illuminance measurement results.

A horizontal luminance of $15.4 \mathrm{~lx}$ was measured on site at a reference point under formal luminaire F4 (see Figure 2); the computer simulation resulted in a horizontal illuminance of $17.0 \mathrm{~lx}$ at the same point within the model.

For step 4, the impact of vertical densification on the lighting quality was calculated. This involved an analysis of the street segment currently featuring formal luminaires provided by the authorities (see Figure 2). These luminaires used $70 \mathrm{~W}$ high-pressure sodium lamps, and the luminous intensity distribution curve of the manufacturer was used for the calculation with a maintenance factor of 0.86 according to Bogotá's lighting standard MUAP ${ }^{39}$. Lighting calculations of five different degrees of vertical densification (zero storeys, one storey, two storeys, three storeys, and four storeys) were conducted for three different scenarios of horizontal densification respectively (a seven-metre-wide street, ${ }^{40} \mathrm{a}$ five-metre-wide street, and a three-metre-wide street) under current lighting conditions (Figure 8). ${ }^{41}$ Three different aspects were analysed: horizontal illuminance on the street (in order to evaluate whether the requirements in Bogotá's lighting standard MUAP would be met), horizontal illuminance on the dwellings' roof (in order to analyse the degree of light pollution), and vertical illuminance on the dwellings' façade (in order to evaluate how much light would potentially enter the interior through windows and disturb the residents, also called light trespass). This detailed analysis was done between formal luminaire F2 and F3 to ensure that there was an adjacent luminaire on either side that might impact the calculation results. For the horizontal illuminance measurements along the street, a one-metre "curved square grid" ${ }^{42}$ of calculation points at ground level was defined and laid out according to the centre axis of the street (see Figure 7). The calculation point spacing of one by one metre was arranged based on the plan view, resulting in a slightly greater spacing due to the inclination of the street. For the horizontal illuminance on the roofs, one calculation point was placed on each roof, one metre distant from the façade edge, perpendicular to the façade midpoint (seen from plan view). For the vertical illuminance on a façade, one calculation point was placed on the midpoint of each façade part (seen from plan view); the calculation point was located 1.2 metres below the ceiling height of the first storey and 1.3 metres below the ceiling height of the second, third, and fourth storeys respectively (since the first storeys tend to be 2.4 metres and the other storeys 2.6 metres high).

39. Alcaldía Mayor de Bogotá D.C. Manual Único de Alumbrado Público (Bogotá: Alcaldía Mayor de Bogotá D.C, 2001).

40. This is the current width at the beginning of the case-study street.

41. The luminaire outreach arms were shortened to 0.6 metre and 0.2 metre for the five-metreand three-metre-wide street respectively in order to take into account the luminous intensity distribution with regards to the street width.

42. A square grid is recommended by the CIE for pedestrian areas of irregular shape; Commission Internationale de l'Eclairage, Road Lighting Calculations. $3^{\text {rd }}$ Edition (Vienna: Commission Internationale de l'Eclairage, 2006). 


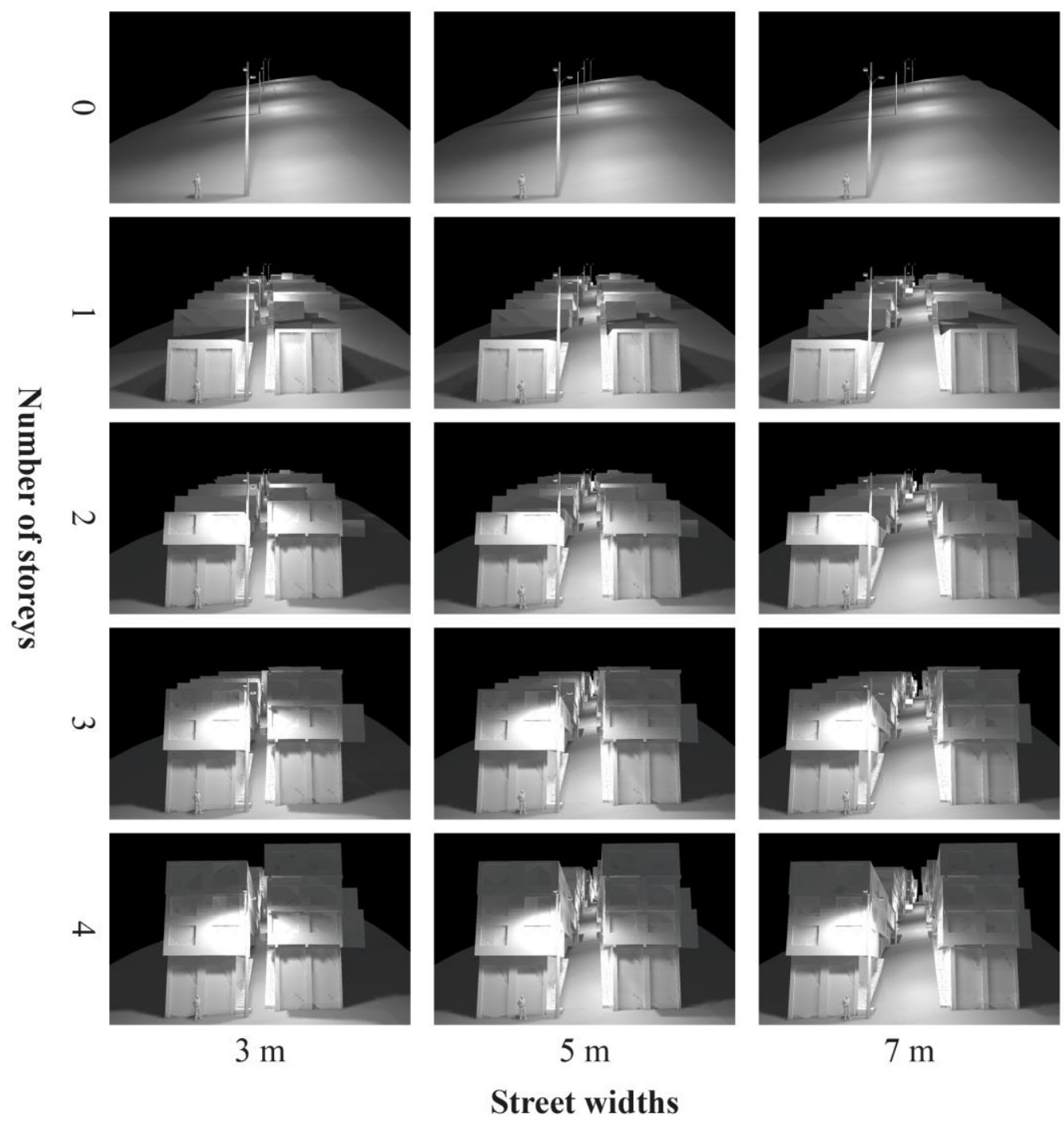

Figure 8. Calculations on the Impact of Building Height and Street Width on Lighting Quality

Source: Kretzer, 2020.

For step 5, the four high-pressure sodium luminaires (evaluated during step 4) were replaced by two alternative lighting solutions (namely a 3.5-metre-high polemounted luminaire (phase 1) as well as a span-wire arrangement mounted 4.1 metres above ground (phase 2) as demonstrated in Figure 9). ${ }^{43}$ These two lighting solutions constitute a two-phase approach in line with the legal status of the settlement: in the initial phase of settlement construction, temporary solar-run lighting is installed by the residents; once the settlement has been legalised and an electrical grid provided, the temporary lighting is replaced by a permanent solution. The aim was to use more luminaires that are more closely spaced in order

43. See: Kretzer, "The Relationship between Public Lighting and Urban Sustainability in Bogotá's Informal Settlements," 2021. 
to increase the local adaptability of the two lighting installations to the informal building extensions (and hence to provide high illuminance uniformity); a further goal was to lower the height of the luminaires to reduce light trespass in the upper interior spaces and to limit light pollution caused by light reflections from the roofs of the dwellings during the early stage of densification (while the roofs are lower than the luminaires). Reducing the height of the luminaires from the current 9 meters also has the benefit of facilitating maintenance. The specific pole shape of the 3.5-metre-high luminaire shifts the pole (at a height of 2.3 metres) 0.6 metre into the street to prevent it from colliding with any overhanging upper storeys and to maintain a wide street space that is unobstructed by luminaire poles (see Figure 10).

These 3.5-metre pole-mounted luminaires were spaced at between 4 to 9.5 metres in the seven-metre-wide street and between 6.5 to 9.5 meters in threemetre-wide street, following a mix of a single-sided and staggered pole arrangement along the street. The span-wire solution was mounted 4.1 metres high on the second storey with a spacing of 15.5 metres in the seven-metre-wide street and 13.5 metres in the three-metre-wide street. A span-wire solution allows a light source to be mounted right above the centre of a street, which further decreases the chance of light being obstructed by informal building extensions protruding from the street edges; furthermore, no poles are required, which prevents obstruction of the informal street space or collision with overhangs. The height and spacing of both luminaire types were determined by several iterative calculations in order not only to meet the average illuminance and illuminance uniformity requirements, but also to avoid a very narrow spacing. ${ }^{44}$ The same calculation points as in step 4 were used for the evaluation of these two alternative lighting solutions.

Two cases were evaluated: the 'best case' and 'worst case' lighting (see 'Results' section) created by the current four high-pressure sodium luminaires compared to the lighting created by the two alternative lighting solutions. The seven-metre-wide street with four storeys was regarded as the 'best case', whereas the three-metre-wide street with two storeys was regarded as the 'worst case'. These two cases resulted in eight scenarios as basis for the simulation in VE/VR, namely the current lighting, the two luminaire types of the alternative approach as well as daylighting - in two street-width situations respectively.

For step 6, a dynamic real-time visualisation framework was developed. The simulations and visualisations were run on multiple (six) CPU cores $\left(9^{\text {th }}\right.$ Generation Intel(R) Core i7(R) CPU 9750H clocked at $2.6 \mathrm{GHz}$ ) with 32GB of RAM. The GPU-accelerated visualisation model runs on a single NVIDIA RTX 2070 with Max-Q Design and 8GB of RAM. The Unreal Engine version 28 is used as the elemental visualisation framework.

The dynamic elements visualised within the visualisation framework comprise the buildings, pedestrians/footfall, luminaire geometries, and photometric characteristics. Each of these elements is further explained in the following section.

44. Moreover, the pole-mounted luminaire had to be within a height that can be installed by informal settlement dwellers; field observations had revealed that 3.5 metres would still be within an acceptable handling height. 
In terms of the dynamic building visualisation, the time component in the form of the historical growth (as documented in the household survey) and anticipated densification process (extrapolation of historical data into future) of the settlement were translated into the visualisation framework by tagging each building with its respective years of storey construction and characteristics such as material or luminaire types. The respective buildings with all their characteristics are visualised for the specific year in which the user is navigating or is located.

Regarding the dynamic footfall visualisation, custom code allows for automated adaptation of pedestrian paths to the topography through an extrusion of multiple spline knots up to the moment of intersection with the topography surface. These intersected spline points are then again connected together and form the walking path of the footfall visualisation.

In input terms, it was necessary to import a geo-located spline as the path of each individual 'agent' (which in this case constitutes data in the form of a detailed night-time participant observation sequence of five minutes), to set the pedestrian walking speed, and to set a start time. The 'agent' appears at the start time and disappears as soon as the sequence is finished. The visualisation timeframe, in this case 30 seconds, can randomly start within the five-minute scenario sequence. The animated 3D characters including character geometry in the form of meshes and virtual skeleton of bones are from Adobe Mixamo.

The built-in Unreal Engine framework is applied to visualise the physical and photometric lighting characteristics within the dynamic environment, which allows for the use of three-dimensional photometric data in the form of IES files (see for example Figure 5) for each luminaire. Nvidia RTX graphics card and Nvidia CUDA technology enable real-time ray tracing to be used and more adequate lighting and reflection results to be achieved. Custom code is applied for the incremental upgrading of luminaires and the response of the luminaire in the form of motion sensors.

The interactive visualisation can be experienced through either front-of-screen or virtual reality in the form of Oculus Rift/Rift $S$ goggles. The visualisation can be experienced either on a fixed/predefined path or open world. Where a predefined path is the input, it is necessary to provide a geolocated spline on which the user can be guided and also enter the movement/walking speed, as with the footfall visualisation framework. For an open world setting, the user can navigate either with a standard gaming setting ('WASD' or arrow keys) or with the Oculus joysticks (Oculus Touch). To experience the growth of the settlement, the user can navigate through years by pressing a dedicated keyboard or Oculus controller button. The respective year to which the user is exposed is displayed on the virtual 'cockpit', graphical user interface (GUI).

\section{Results}

The results of the lighting calculations of step 4 are presented below (Table 1). Various conclusions can be drawn regarding the different lighting characteristics calculated: 
1) Average illuminance (lx) on street surface:

The more storeys, the higher the average illuminance. It can be assumed that this is caused by more square meters of dwelling façade that reflect light from the luminaires on to the street. Bogotás lighting standard requires for footpaths an average illuminance of at least $71 \mathrm{x}^{45}$; this lighting level is achieved in all 15 scenarios.

2) Minimum illuminance (lx) and illuminance uniformity $U_{0}$ on street surface:

The wider the street, the higher the minimum illuminance and hence the illuminance uniformity. $^{46}$ In this case, the lowest illuminance was calculated behind an informal building extension (see Figure 11) that shades the direct light emitted by one of the four luminaires. It seems that the wider the street, the more light could be emitted to surfaces nearby (that then reflect this light on to the calculation point measuring the lowest illuminance), since informal building structures (such as levelling foundations, porches, separation walls, and overhangs) protruded less into the street's centre. According to Bogotá's lighting standard ${ }^{47}$, the uniformity $\mathrm{U}_{0}$ should be at least 0.33 - however, in none of the 15 scenarios is this uniformity achieved.

3) Maximum illuminance on a roof (lx):

In all three street-width scenarios, most of the light is emitted on to the roofs when there is only one or two storeys. Significantly less light reaches the roof of three- and four-storey buildings; in this case, the dwellings have heights comparable to the street luminaires themselves - and the light therefore tends to be emitted against the façades. This makes sense: if a luminaire is located higher than the roof (and if the luminous intensity distribution of the luminaire is not focusing the light very precisely on to the street surface), a lot of light can be expected to be emitted on to the roofs. However, such light is partly reflected by the roofs into the sky, creating so-called light pollution. Light pollution has a negative impact on the night-time fauna: for example, migrating birds may be disorientated. ${ }^{48}$

4) Maximum illuminance on a façade (lx):

In all three street-width scenarios, most of the light is emitted on to a façade of the four-storey scenario, with a maximum illuminance of $95.0 \mathrm{~lx}$ in the three-metre-wide street (on a calculation point of the third storey). However, light that is emitted on to a façade may enter a dwelling through windows and affect the residents' circadian rhythms. ${ }^{49}$ The maximum

45. See: Alcaldía Mayor de Bogotá D.C., Manual Único de Alumbrado Público, 2001.

46. Illuminance uniformity $\mathrm{U}_{0}$ is here defined as the minimum illuminance $\mathrm{E}_{\min }$ divided by the average illuminance $\mathrm{E}_{\mathrm{av}}$.

47. See: Alcaldía Mayor de Bogotá D.C., Manual Único de Alumbrado Público, 2001.

48. E. E. Goronczy, Lichtverschmutzung in Metropolen: Analyse, Auswirkungen und Lösungsansätze (Wiesbaden: Springer Vieweg, 2018).

49. Ibid. 
illuminance on a window should not exceed $1 \mathrm{~lx},{ }^{50}$ but in these scenarios, it is up to 95 times higher.

Table 1. Lighting Calculation Results

\begin{tabular}{|c|c|c|c|c|c|c|c|c|c|c|c|c|c|c|c|}
\hline Street width & \multicolumn{5}{|c|}{$7 \mathrm{~m}$} & \multicolumn{5}{|c|}{$5 \mathrm{~m}$} & \multicolumn{5}{|c|}{$3 \mathbf{m}$} \\
\hline Number of storeys & 4 & 3 & 2 & 1 & $\mathbf{0}$ & 4 & 3 & 2 & 1 & $\mathbf{0}$ & 4 & 3 & 2 & 1 & $\mathbf{0}$ \\
\hline $\begin{array}{l}\text { Average illuminance on } \\
\text { street surface } E_{\mathrm{av}}(\mathbf{l x})\end{array}$ & 11.0 & 10.8 & 10.4 & 9.8 & 9.3 & 11.3 & 11.0 & 10.5 & 9.8 & 9.3 & 9.1 & 8.9 & 8.8 & 8.6 & 8.5 \\
\hline $\begin{array}{l}\text { Min. illuminance on } \\
\text { street surface } E_{\min }(\mathbf{l x})\end{array}$ & 0.6 & 0.5 & 0.3 & 0.2 & 1.7 & 0.5 & 0.4 & 0.3 & 0.1 & 1.8 & 0.2 & 0.1 & 0.1 & 0.1 & 1.8 \\
\hline $\begin{array}{l}\text { Illuminance uniformity } \\
\text { on street surface } U_{0}\end{array}$ & 0.06 & 0.05 & 0.03 & 0.02 & 0.18 & 0.05 & 0.04 & 0.02 & 0.01 & 0.19 & 0.02 & 0.02 & 0.01 & 0.01 & 0.21 \\
\hline $\begin{array}{l}\text { Max. illuminance on a } \\
\text { roof }(\mathbf{l x})\end{array}$ & 0.1 & 3.9 & 14.0 & 15.0 & $\mathrm{n} / \mathrm{a}$ & 0.1 & 12.0 & 23.0 & 33.0 & $\mathrm{n} / \mathrm{a}$ & 0.2 & 6.5 & 79.0 & 50.0 & $\mathrm{n} / \mathrm{a}$ \\
\hline $\begin{array}{l}\text { Max. illuminance on a } \\
\text { façade }(\mathbf{l} \mathbf{x})\end{array}$ & 33.0 & 32.0 & 32.0 & 20.0 & $\mathrm{n} / \mathrm{a}$ & 52.0 & 50.0 & 39.0 & 20.0 & n/a & 95.0 & 91.0 & 29.0 & 7.6 & $\mathrm{n} / \mathrm{a}$ \\
\hline
\end{tabular}

Source: Kretzer, 2020.

Defining a 'worst case' and a 'best case' scenario for the alternative lighting approach (step 5) cannot be done in an absolutely clear way here, since there are a variety of characteristics that are not all consistently good or bad in each of the different densification scenarios. Hence, the characteristics need to be weighted: average illuminance $\mathrm{E}_{\mathrm{av}}$ and illuminance uniformity $\mathrm{U}_{0}$ are given first priority because they are the only ones defined in the local lighting standard MUAP. The degrees of light pollution (illuminance on a roof) and light trespass (illuminance on the façades) are given lower priority; however, since light trespass caused by high illuminance values on a façade could be mitigated by curtains on windows, it is regarded as a more minor issue in this context (third priority) compared to the light pollution (second priority) resulting from light reflected by the roofs. As a result, the seven-metre street width with four storeys scenario was selected as the 'best case' scenario, since it over-fulfils the average illuminance requirements, it has the highest illuminance uniformity value, the lowest maximum illuminance values on a roof, and the second lowest maximum illuminance value on the façades within the three- and four-storey scenarios. The three-metre street width with two storeys scenario was selected as the 'worst case' scenario since it has the lowest value of illuminance uniformity and the highest degree of illuminance on a roof, even though the maximum illuminance value on the façade was on the low side compared to most of the other scenarios.

50. Commission Internationale de l'Eclairage, Guide on the Limitation of the Effects of Obstrusive Light from Outdoor Lighting Installations (Vienna: Commission Internationale de l'Eclairage, 2003). 


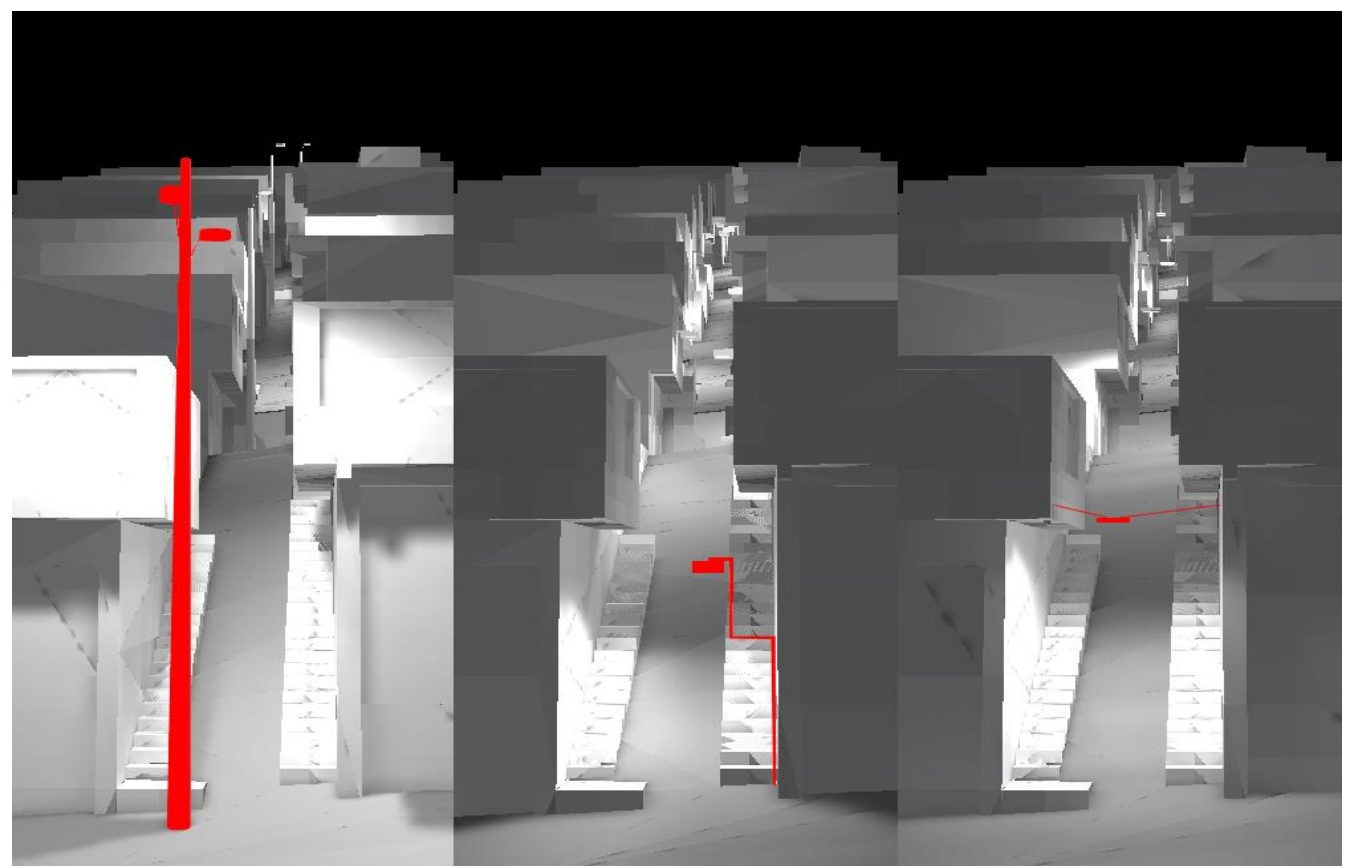

Figure 9. The Current Lighting Approach (left-hand side) vs. the Two-Phase Alternative Lighting Approach (Phase 1: 3.5-Metre-High Pole-Mounted Luminaires, Phase 2: Span-Wire-Mounted Luminaires) in the Scenario with a Three-Metre-Wide Street and Two-Storey Dwellings

Source: Kretzer, 2020.

The alternative two-phase lighting approach (see Figure 9) evaluated in step 5 improved all lighting characteristics created by the current lighting condition with the exception of just one criterion:

Regarding the 'best case scenario' (seven-metre street width with four storeys), applying the 3.5-metre-high pole-mounted luminaires created an illuminance uniformity $\mathrm{U}_{0}$ of $0.34\left(\mathrm{E}_{\mathrm{av}}=12.3 \mathrm{~lx}\right)$, a maximum illuminance on a roof of $0 \mathrm{~lx}$, and a maximum illuminance on a façade of $9.2 \mathrm{~lx}$.

Applying the span-wire-mounted luminaires resulted in an illuminance uniformity $\mathrm{U}_{0}$ of $0.36\left(\mathrm{E}_{\mathrm{av}}=10.1 \mathrm{~lx}\right)$, a maximum illuminance on a roof of $0 \mathrm{~lx}$, and a maximum illuminance on a façade of $9.8 \mathrm{~lx}$.

Regarding the 'worst case scenario' (three-metre street width with two storeys), applying the 3.5-metre-high pole-mounted luminaires created an illuminance uniformity $\mathrm{U}_{0}$ of $0.40\left(\mathrm{E}_{\mathrm{av}}=11.6 \mathrm{~lx}\right)$, a maximum illuminance on a roof of $1.1 \mathrm{~lx}$, and a maximum illuminance on a façade of $23 \mathrm{~lx}$.

Applying the span-wire-mounted luminaires resulted in an illuminance uniformity $\mathrm{U}_{0}$ of $0.36\left(\mathrm{E}_{\mathrm{av}}=8.3 \mathrm{~lx}\right)$, a maximum illuminance on a roof of $0.1 \mathrm{~lx}$, and a maximum illuminance on a façade of $32 \mathrm{~lx}$. The $32 \mathrm{~lx}$ on the façade created by the span-wire installation in the 'worst case scenario' was $3 \mathrm{~lx}$ higher than under the current nine-metre-high pole-mounted lights, and hence it constitutes the only criterion that was not improved by the alternative lighting approach. However, it is likely that the locations of the windows are already determined when the spanwires are attached to the façades. If a luminaire was initially planned to be mounted in front of a window, it could instead be mounted either below or next to 
such window: the uniformity of 0.36 exceeds the uniformity requirement of 0.33 , and hence a little flexibility regarding the luminaire position would be possible. Mounting a luminaire below or next to a window reduces its negative effect on the interior space caused by high vertical illuminance. In contrast, such flexibility cannot be realised by a luminaire that is pole-mounted, nine metres high, and possibly installed before the storeys have been built.

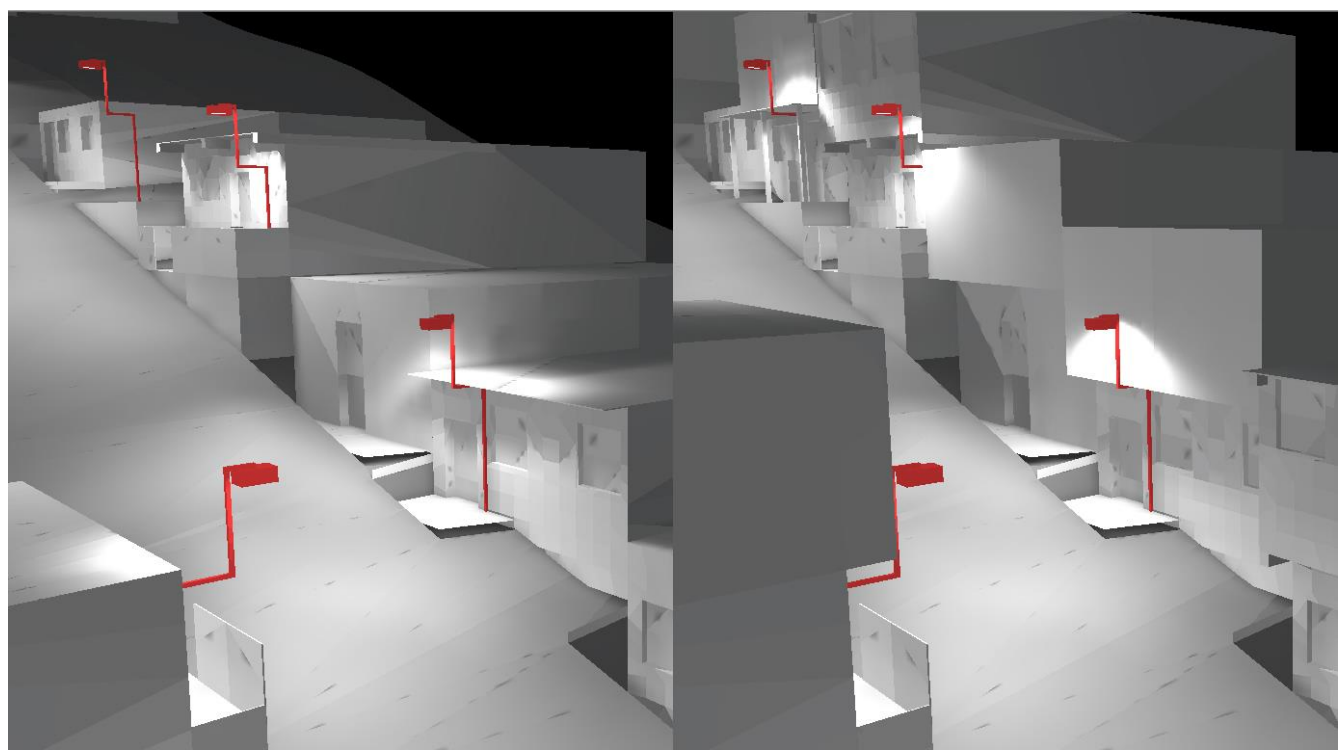

Figure 10. Foreseeing Vertical Densification: the Pole of the 3.5-Meter-High Luminaire (Used during Phase 1) does not Collide with Potentially Overhanging Upper Storeys (see figure on the right-hand side) and Results in a Wide Street Space that is Unobstructed by Luminaire Poles.

Source: Kretzer, 2020.

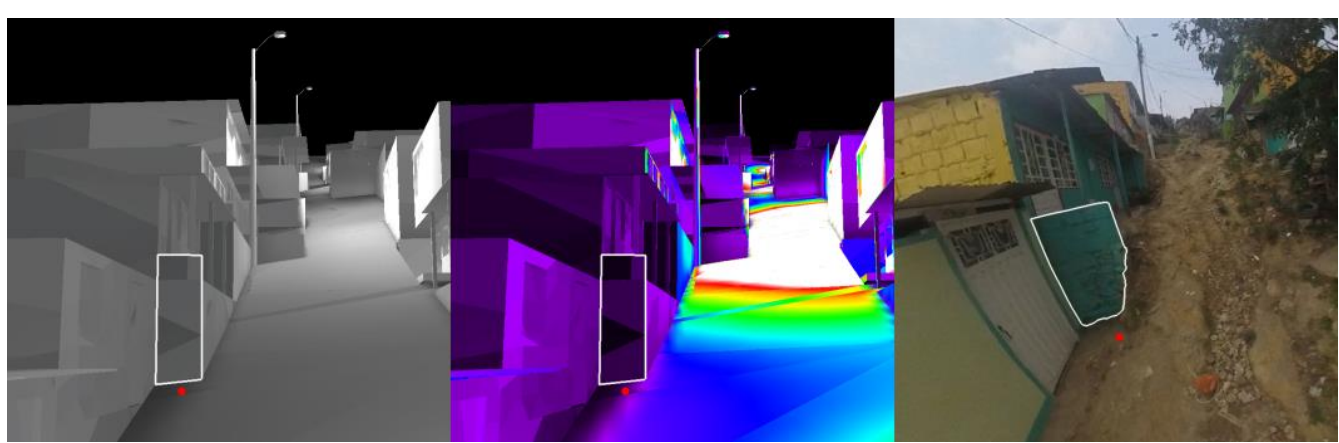

Figure 11. The Minimum Illuminance Value $E_{\min }$ Illustrated by a Lighting Calculation Rendering (left-hand side), a Lighting Calculation Pseudo Colour Image (middle), and a Photograph Taken by a $360^{\circ}$ Camera (right-hand side), the Low Value of $E_{\min }$ (indicated by the red dot) is Caused by an Informal Building Extension (indicated by the white frame).

Source: Kretzer, 2020. 
Apart from the lighting quality, the future vertical densification projection revealed shortcomings regarding the luminaire product design: it was found that all four formal luminaire poles collided with at least the fourth storey.

Regarding the VE/VR framework, this study shows the feasibility of (1) a method presented for the spatial and temporal documentation of rapidly changing informal environments in VE, (2) the medium for visualising such data in VR, and (3) the ability to generate lighting-specific features in multiple future scenarios in VE/VR.

(1) Custom code enables state-of-the-art game-engine technology to be enhanced with the capability to use temporal large-scale quantitative as well as empirical data sets in an automated manner. This is primarily a matter of visualising the historical as well as the projected future incremental development of architectural structures and their changes in materialisation terms (see Figure 12). The output in the form of common planning documents such as sections and plans can be further used in planning processes. The visualisation of motion patterns of pedestrians in the form of animated human skeletons is a further key concern (see Figure 13).

(2) A custom graphical user interface (GUI) helps navigate the virtual environment by displaying in text form the current year that is being visualised or the tasks/functionalities that the user can access.

Based on state-of-the-art game-engine technology, a range of media can be deployed to create visualisation output: in this case, VR. Since the output is a visual one, the viewer can use this medium for a visual inspection of the content displayed, for example any types of pole and overhang collisions or lighting non-uniformities. If the framework is documented, this presented workflow can be used for future studies, scaled, and transferred to other contexts.

(3) Custom code allows the expansion of state-of-the-art game-engine technology to accommodate dynamic incremental changes in luminaire types and their geometries. Custom code allows for a dynamic response to user behaviour in the form of additional lighting attributes such as motion sensors. Since all of these parameters and attributes can be changed dynamically in the form of a custom graphical user interface (GUI), the tool is particularly useful for iterative design processes and scenario planning. 

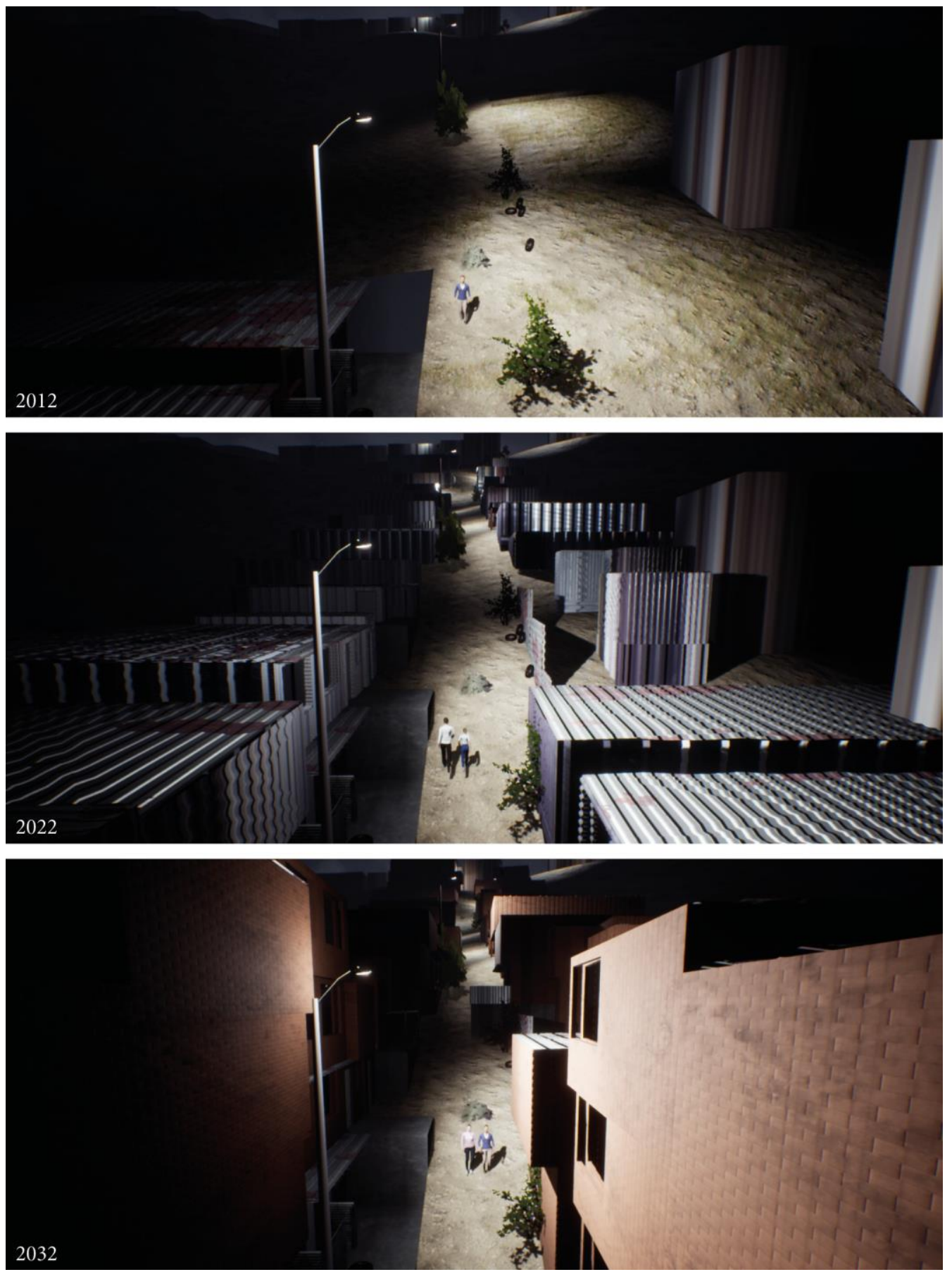

Figure 12. Sample Situations from the Real-Time VE Simulation over Time Displaying the Environment, the Vertical Building Densification, and the Footfall. The '2012' Image, for Example, Clearly Illustrates the Delay of Formal Luminaire Provision in the Upper Part of the Settlement that had been already Covered with Informal Dwellings in 2010.

Source: Walczak, 2020. 

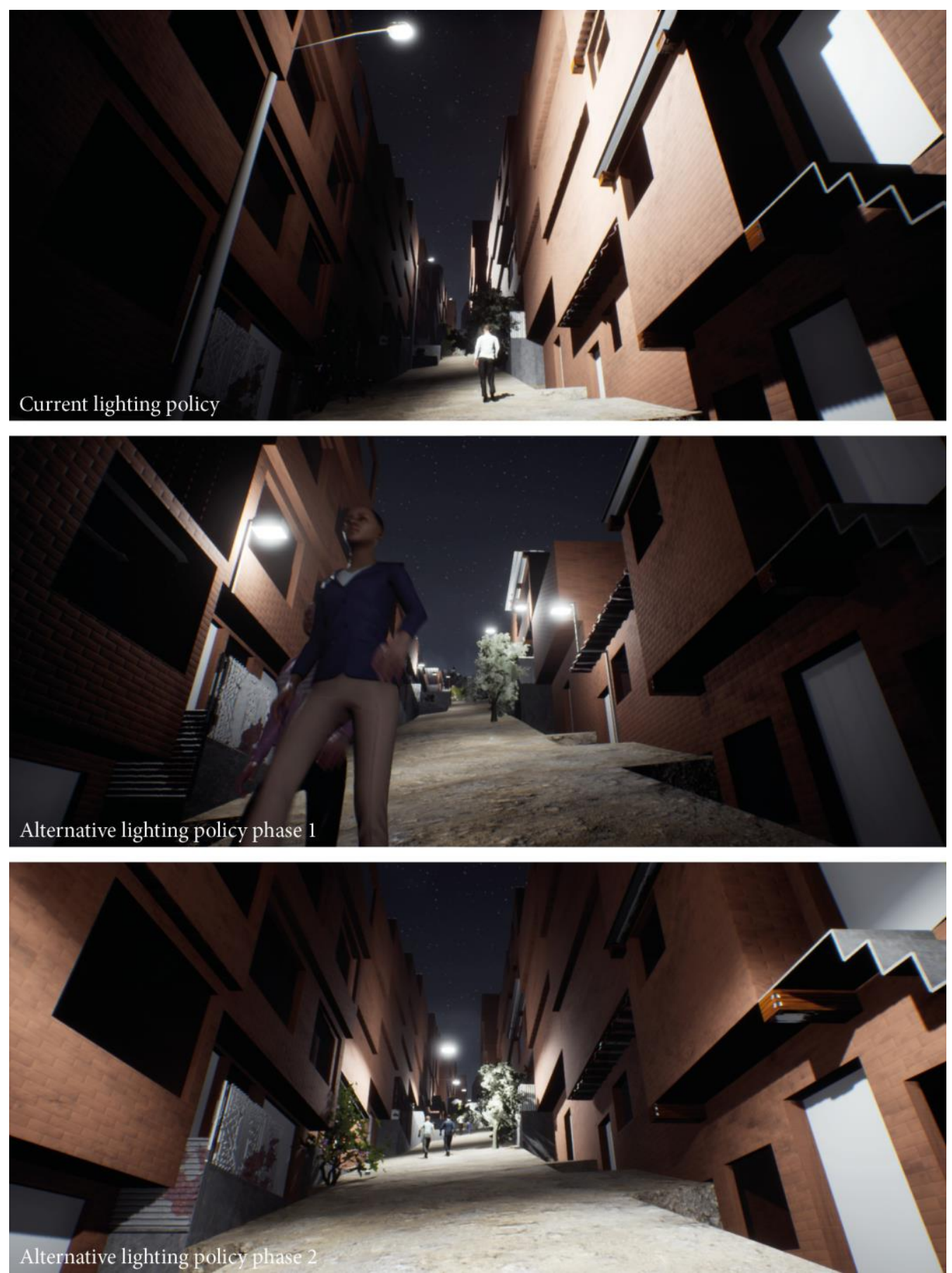

Figure 13. Scenario-Based Decision-Making Visualisation for a Multitude of Different Options, in this Case the Current Lighting Approach in the Case-Study Street as a 'Seven-Metre-Wide Street with Four Storeys Scenario', versus the TwoPhase Alternative Lighting Approach. All of the Scenarios Include Temporal Data such as Densification and Footfall. Visual Inspection Illustrates not only the Lighting Effect, but also Enables Detection of how the Light Column Collides with the Fourth Storey (see figure on 'Current lighting policy').

Source: Walczak, 2020. 


\section{Discussion and Conclusions}

To date, only sparse research has been conducted on the lighting quality of formal luminaires installed in informal environments. As regards vertically densifying informal settlements, it seems that nobody has previously tried to assess the resulting lighting conditions in a systematic way. By doing so, this paper has shown that the application of one type of nine-metre-high pole-mounted luminaires with a spacing of around 30 meters has several limitations: it results in low illuminance uniformity values, it creates high illuminance values on the roofs and hence light pollution, and it causes high illuminance values on façades and thus potential light trespass into the dwelling interiors.

Furthermore, this paper has shown that the illuminance uniformity limitations can be overcome and both light pollution and light trespass significantly reduced by a two-phase lighting approach: a 3.5-metre pole-mounted solution with a pole shape that anticipates the future building shape with a varying spacing of between 4 and 9.5 metres in the seven-metre- and between 6.5 and 9.5 metres in the threemetre-wide streets, followed by a span-wire solution mounted 4.1 metres high on the second storey with a constant spacing of 15.5 metres in the seven-metre-wide street and 13.5 metres in the three-metre-wide street. The pole-mounted luminaires were positioned with an unequal spacing between the luminaires due to the complex architectural characteristics of this informal street: the luminaires had to be adapted to the given environment - and this possibility is the advantage of such a lighting approach. The 3.5-metre-high pole-mounted luminaire allows for a flexible adaption due to its short spacing and its pole shape that prevents collision with the overhangs of the upper storeys as are common in Bogotá. Since span-wire lighting can be mounted right above the centre of a street, it also does not collide with overhangs and provides good uniformity values (which in this study are further ensured by relatively short spacing). Furthermore, it offers the possibility to be mounted further away from windows in order to prevent light trespass if necessary. Moreover, the span-wires can be mounted diagonally between buildings if no opposite façade mounting option is available. Once the second storeys are built, almost no illuminance is created on the roofs, since the luminaires hang lower and hence light pollution is reduced significantly.

The 3.5-metre pole-mounted solution (given the photometric characteristics used in the present study) would be able to address the current lighting quality shortcoming of the self-built 'informal' luminaires. If they were further equipped with a solar PV panel and a battery as well as both a photo and motion sensor, they could be installed instantly, overcoming the delay caused by the legalisation process.

Even though the shortcomings of the current formal and informal lighting approach as well as the improvements through the alternative approach can be proved using computer calculations, the question is how to translate those findings for the benefit of policy-making stakeholders who could potentially advocate this alternative approach. Average illuminance $\mathrm{E}_{\mathrm{av}}$, minimum illuminance $\mathrm{E}_{\mathrm{min}}$, and illuminance uniformity $\mathrm{U}_{0}$ are abstract values and correspond to certain technological definitions that are unlikely to be understood by people outside the 
lighting profession. However, virtual reality offers the possibility to translate those abstract values into a visual experience. While VR does not of course have the same visual quality as a real environment, it can create results that are close to it. ${ }^{51}$

Compared to a lighting evaluation based on numeric calculation results (Table 1), static renderings, or pseudo colour images (Figure 11), a VE offers several additional possibilities for informal settlement lighting planning:

1) An observer can freely explore a three-dimensional environment from an eye-level perspective instead of relying on predefined viewpoints or camera paths. Semi-public building extensions can often be found in informal settlements. It seems fair that the lighting conditions in those semi-public/semi-private areas do not need to fulfil the street lighting standards. However, they are still part of the visual scene and may still have a negative impact on the perception of night-time space. Such building extensions may, for example, serve as a hiding place for a criminal. By being able to move freely through an environment, the observer can evaluate from different perspectives how a lighting solution impacts on such semi-public/semi-private public space.

2) The viewing radius in VE/VR is unrestricted, allowing the observer to turn around or to look up and down. Moreover, head-mounted displays (HMD) adapt the viewing direction to the natural movement of the head. This allows for a better evaluation of aspects related to the built environment such as the feeling of enclosure in a very narrow street.

3) A VE can include moving objects such as people which offers the possibility of exploring the degree of reassurance/fear of crime (resulting from the lighting design) in a more realistic way.

4) Moreover, for the evaluation of a lighting design's effect on the fear of crime at night, it is also important to analyse the degree of fear during the day - in order to determine people's baseline level of fear in a certain area. ${ }^{52}$ Brillembourg and Klumpner ${ }^{53}$ show that the daylight penetration into a dense informal urban fabric can be very low (i.e. $7 \%$ in their case study). Hence, the analysis of fear of crime in such environments appears to be very complex. In a VE, a daylight scenario can be integrated as a direct comparison to the night-time lighting, which helps to study such effects visually. Thus, it may even be possible to simulate dynamic elements of a daytime condition such as wind, moving clouds and trees, fog, or rain in VE/VR ${ }^{54}$ (see Figure 14).

51. Chen, Cui and Hao, "Virtual Reality in Lighting Research: Comparing Physical and Virtual Lighting Environments," 2019.

52. Fotios, Liachenko Monteiro and Uttley, "Evaluation of Pedestrian Reassurance Gained by Higher Illuminances in Residential Streets using the Day-Dark Approach," 2019.

53. Brillembourg and Klumpner, "The Simple and Complex," 2005.

54. Walczak, "Impact of Urban Planning on Air Quality: The Consequences of the Mismatch between Natural Wind Flows and Building Typologies," in Transitioning to Sustainable Cities and Communities (ed.) H. Klumpner and K. E. Papanicolaou. Basel: MDPI, 2021. [In Review]. 
5) Physical transformation of the built environment including materialisation (e.g. horizontal and vertical densification over time) can be dynamically illustrated (see Figure 12).

6) Dynamic lighting technology such as sensor-driven adaptive lighting can be simulated.

7) By integrating sound, audio perception of an environment can be added to the given visual perception. This is likely to have an impact for example on expressing the degree of community confidence and hence informal social control.

8) Similarly to commonly used monitor hoods, VR enables screen surroundings to be masked with an HMD. This allows the viewer just to see the virtual image rather than the additional context of the viewing device. In this way, the observer is more strongly disconnected from the real world and not visually distracted.

9) VR/VE is well embedded as an interface between multiple existing and conventional digital tools and large-scale data sources. This makes it easier to automatically incorporate and combine complex characteristics of informal environments, such as a steep terrain, traffic simulation, and cadastral data into the virtual model.
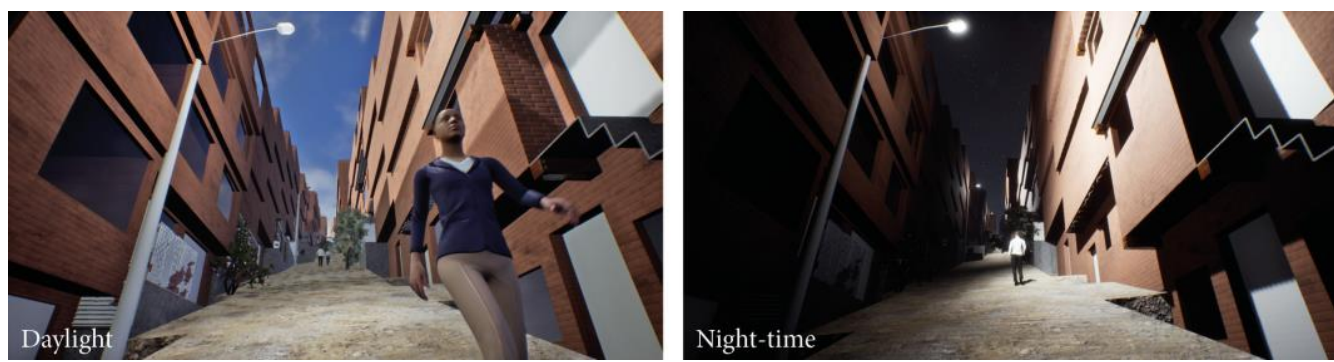

Figure 14. The Unreal Engine Framework Allows Daylight Simulation in comparison to the Night-Time Lighting Conditions.

Source: Walczak, 2020.

Apart from the lighting planning, the VE/VR tool presented above has significant potential for lighting policy making in informal settlements. First of all, access to informal settlements is often limited for outsiders - both during the day and at night. This digital twin of a case-study street allows free visual exploration of the highly complex built environment that also contains temporal and motion data (including information on the age, gender, and activities of people) translated into a visual experience. The specific nature of incremental building growth and its direct interplay with the lighting is embedded into this VE/VR tool as well, based on survey data.

Furthermore, VE is not limited in terms of scale: it could range from a oneroom dwelling to a whole city - and many of the required data for the creation of the VE can automatically be processed from sources such as satellite images as well as cadastral and census data. Huge parts of cities in the Global South may be 
informally built: $50 \%$ of Bogotá, for example, is of informal origin. ${ }^{55}$ For policy makers, a VE/VR offers the opportunity to assess large-scale lighting scenarios, not only with regards to lighting quality but also regarding aspects such as legalisation processes, luminaire maintenance, lighting financing, and electricity consumption. In addition to the application of lighting planning, the VE/VR offers the opportunity for policy makers to translate cadastral data and satellite imagery into a visual archive of city development. The data in the tool presented could automatically reconstruct a large scale informal settlement based on cadastral data and satellite imagery, with an uncertainty of only around one meter per façade which might be caused by overhangs. However, since informal settlements are not bound to building standards, which makes it impossible to accurately predict future building characteristics, this one meter of inaccuracy can still serve as a planning basis. Furthermore, the lighting design could even be executed in a way to compensate for such unpredictable building features that may evolve in the future of a settlement.

For the reasons stated above, a VE appears to be a promising tool for the evaluation of lighting technologies in informal environments in addition to common lighting calculations. It can 'communicate' the lighting characteristics to different stakeholders in a manner understandable to the layman - for example to the non-technical staff of a city's public lighting department, to the urban planning department, to NGOs, to international donors, and to the residents of informal settlements. Moreover, the lighting characteristics can be presented in a temporal way, which would be a helpful evaluation tool for policy makers because lighting policy consequences can be projected over several decades.

However, so far these are just theoretical considerations. Further empirical research would be required to test whether (and if so, to what degree) VEs can improve the communication of lighting characteristics compared to numerical calculation results, static renderings, or pseudo colour images. Another important question would be what level of detail would be required to adequately create an illuminated VE in terms of, for instance, the textures, the amount of greenery, the presence of sound, or the presence and behaviour of people.

55. Hernández-García, Public Space in Informal Settlements: The Barrios of Bogotá, 2013. 


\section{Acknowledgments}

This work was supported by an ETH Zurich ISTP Research Incubator Grant and by a Leading House for the Latin American Region Research Grant.

The authors would like to thank Dr. Ndaona Chokani, Prof. Hubert Klumpner, Prof. Dr. Andreas Wenger and Prof. Dr. Reza Abhari from ETH Zurich, Prof. Anton Falkeis from the University of Applied Arts Vienna as well as Prof. Jaime Hernández Garcia and Sandra Caquimbo Salazar from Pontificia Universidad Javeriana for their academic advice. Zumtobel Lighting $\mathrm{GmbH}$ offered photometric measurements in its goniophotometer, and Konica Minolta Sensing Europe B.V. Dietikon provided an illuminance meter, both free of charge.

\section{Bibliography}

Alcaldía Mayor de Bogotá D.C. Manual Único de Alumbrado Público. [Unique Manual of Public Lighting.] Bogotá: Alcaldía Mayor de Bogotá D.C, 2001.

Beck, J. "Hyper Reality Pop.” In Virtual Reality, 240-249. Edited by D. Landwehr. Basel: Christoph Merian Verlag, 2019.

Bhatt, V. and W. Rybczynski. "How the Other Half Builds." In Time-Saver Standards for Urban Design, 1.3-1 - 1.3-12. Edited by D. Watson, A. Plattus and R. Shibley. New York/Chicago/San Francisco/Lisbon/London/Madrid/Mexico City/Milan/New Delhi /San Juan/Seoul/Singapore/Sydney/Toronto: McGraw-Hill, 2003.

Boyce, P. R. "The Benefits of Light at Night." Building and Environment 151 (2019): 356-367.

Brillembourg, A. and H. Klumpner. "The Simple and Complex." In Informal City: Caracas Case, 216-226. Edited by A. Brillembourg, K. Feireiss and H. Klumpner. Munich/Berlin/London/New York: Prestel, 2005.

Chamilothori, K., J. Wienold and M. Andersen. "Adequacy of Immersive Virtual Reality for the Perception of Daylit Spaces: Comparison of Real and Virtual Environments." The Journal of the Illuminating Engineering Society 15, no. 2-3 (2019): 203-226.

Chen, Y., Z. Cui and L. Hao. "Virtual Reality in Lighting Research: Comparing Physical and Virtual Lighting Environments." Lighting Research \& Technology 51, no. 6 (2019): 820-837.

Commission Internationale de l'Eclairage. Guide on the Limitation of the Effects of Obstrusive Light from Outdoor Lighting Installations. Vienna: Commission Internationale de l'Eclairage, 2003. . Road Lighting Calculations. $3^{\text {rd }}$ Edition. Vienna: Commission Internationale de l'Eclairage, 2006.

Debray, R. Einfuihrung in die Mediologie. [Introduction to Mediology.] Bern: Haupt Verlag, 2003.

Döllner, J., K. Baumann and H. Buchholz. "Virtual 3D City Models as Foundation of Complex Urban Information Spaces." $11^{\text {th }}$ International Conference on Urban Planning and Spatial Development in the Information Society. Vienna: CORP Competence Center for Urban and Regional Development, 2006, 107-112.

Doyle, M. R., S. Savić and V. Bühlmann. Ghosts of Transparency: Shadows Cast and Shadows Cast out. Basel: Birkhäuser, 2019.

Fotios, S. and J. Uttley. "Illuminance Required to Detect a Pavement Obstacle of Critical Size.” Lighting Research \& Technology 50, no. 3 (2018): 390-404. 
Fotios, S., A. Liachenko Monteiro and J. Uttley. "Evaluation of Pedestrian Reassurance Gained by Higher Illuminances in Residential Streets using the Day-Dark Approach." Lighting Research \& Technology 51, no. 4 (2019): 557-575.

Goronczy, E. E. Lichtverschmutzung in Metropolen: Analyse, Auswirkungen und Lösungsansätze. [Light Pollution in Metropolises: Analysis, Effects and Solutions.] Wiesbaden: Springer Vieweg, 2018.

Gouverneur, D. Planning and Design for Future Informal Settlements: Shaping the SelfConstructed City. Abingdon / New York: Routledge, 2015.

Greengard, S. Virtual Reality. Cambridge / London: The MIT Press, 2019.

Hernández-García, J. Public Space in Informal Settlements: The Barrios of Bogotá. Newcastle upon Tyne: Cambridge Scholar Publishing, 2013.

Kaganskiy, J. "New Ways of Seeing and Perceiving." In The Unframed World, Virtual Reality as Artistic Medium, 58-64. Edited by Haus der elektronischen Künste Basel. Basel: Christoph Merian Verlag, 2017.

Kamalipour, H. and K. Dovey. "Incremental Urbanism." In Mapping Urbanities: Morphologies, Flows, Possibilities, 249-267. Edited by K. Dovey, E. Pafka and M. Ristic. Abington/New York: Routledge, 2018.

Kamalipour, H. and K. Dovey. "Mapping the Visibility of Informal Settlements." Habitat International 85 (2019): 63-75.

Kretzer, D. M. "High-Mast Lighting as an Adequate Way of Lighting Pedestrian Paths in Informal Settlements?" Development Engineering (2020) DOI=10.1016/j.deveng. 2020.100053.

. "The Relationship between Public Lighting and Urban Sustainability in Bogotá's Informal Settlements." In Transitioning to Sustainable Cities and Communities. Edited by H. Klumpner and K. E. Papanicolaou. Basel: MDPI, 2021. [In Review].

Landwehr, D. (Ed.). Virtual Reality. Basel: Christoph Merian Verlag, 2019.

Leslie, R. P. and P. A. Rodgers. The Outdoor Lighting Pattern Book. New York: McGrawHill Publishers, 1996.

Majale, M. Enabling Shelter Strategies: Design and Implementation Guide for Policymakers. Nairobi: UN-Habitat, 2011.

Mitchell, W. J. Bildtheorie. [Image Theory.] Frankfurt am Main: Suhrkamp, 2018.

Neufert, E. Bauentwurfslehre. 42. [Building Design Theory.] Wiesbaden: Springer Vieweg, 2019.

Ravindra Prasad D. and A. Malla Reddy. Environmental Improvement of Urban Slums: The Indian Experience. Hyderabad: Booklinks Corporation, 1994.

Schechtner, K. "Big Data for Urban Change: Debunking the Myth \& a Way Forward." In Urban Change: Social Design - Arts as Urban Innovation, 117-123. Edited by A. Falkeis. Basel: Birkhäuser, 2017.

Taubenböck, H., N. J. Kraff and M. Wurm. "The Morphology of the Arrival City - A Global Categorization based on Literature Surveys and Remotely Sensed Data." Applied Geography 92 (2018): 150-167.

UN-Habitat. The Challenge of Slums: Global Report on Human Settlements 2003. London/ Sterling, VA: Earthscan, 2003.

United Nations 2015. Sustainable Development Goals. Retrieved from: www.un.org/sus tainabledevelopment/cities/. [Accessed 18 April 2019].

Walczak, M. "Qualitative Visualization of Quantitative Urban Models Impacting Policy Decision Making: A Case Study of Urban Infrastructure Interventions." 3. Doktorand_innen Symposium der Architektur. Linz: Kunstuniversität Linz, 2019. . "Impact of Urban Planning on Air Quality: The Consequences of the Mismatch between Natural Wind Flows and Building Typologies." In Transitioning to 
Sustainable Cities and Communities. Edited by H. Klumpner and K. E. Papanicolaou. Basel: MDPI, 2021. [In Review].

Ward, P. M. "The Practice and Potential of Self-Help Housing in Mexico City." In SelfHelp Housing: A Critique, 175-208. Edited by P. M. Ward. London: Mansell Publishing Limited, 1982. 